\title{
Ultimate Strength Assessment of Plated Steel Structures with Random Pitting Corrosion Damage
}

Renhua Wang ${ }^{1 * *}$, R Ajit Shenoi ${ }^{2}$, Adam Sobey $^{3 .}$

wrhchina@163.com

1. Department of Civil Engineering, Jiangsu University of Science of Technology, Zhenjiang 212003, China

2. Southampton Marine and Maritime Institute, University of Southampton, Boldrewood Innovation Campus, Southampton SO16 7QF, UK

3. Fluid Structure Interactions Group, University of Southampton, Boldrewood Innovation Campus, Southampton SO16 7QF, UK

\section{Abstract}

Pitting corrosion poses a threat to plated steel structures serving in aggressive corrosion environments. This paper involves numerical studies on the structural behaviour and ultimate strength reduction of plated steel structures due to random pitting damage. Stochastic simulations were used to model the random nature of the pitting corrosion varying pitting shape, depth and distribution. A series of nonlinear analyses were performed on unstiffened plates and stiffened panels to understand the mechanisms of structural collapse due to random pitting damage.

Empirical formulae were derived respectively for the prediction of ultimate strength reductions of unstiffened plates and stiffened panels in terms of regression analysis from the numerical results. Random pitting corrosion induces a variation and reduction in ultimate strength, and can lead to a transition in failure mode. The collapse of pitted structures under uniaxial compression has a feature that the onset of plasticity initiates in the areas close to the unloaded edge of the structure, and propagates into a continuous plasticity region linking the pits with highly concentrated stress. The pitted area with intensively stress-concentrated pits undergoes a locally amplified deformation that determines the failure mode, leading to structural failure.

Keywords: plated steel structure; ultimate strength; pitting corrosion; stochastic simulation 


\section{Introduction}

Ultimate strength is of primary concern in determining realistic safety margins for a structural system such as bridges, ships and marine structures [1, 2]. In a long-term aggressive environment, such steel structures are susceptible to pitting corrosion [3-5]. Pitting is a localized accelerated dissolution of metal that occurs as a result of a breakdown in the protective passive film on the metal surface [6]. A large number of complex influential factors affect the initiation and progress of pitting corrosion. Conventional surveys of corroded structures can only provide statistical rather than specific corrosion information [7]. Modelling randomly distributed pitting damage is still a challenge for ultimate strength assessment $[8,9]$. Consequently, assessing ultimate strength of the corroded structure usually depends on the limited corrosion data of some measured pits statistically collected from the corrosion surveys. A variation of ultimate strength may result from the uncertainty in the corrosion scenarios described by these limited corrosion data [10].

A considerable amount of research has been performed on the collapse strength of corroded plates and box-girders subject to general corrosion leading to relatively uniform thinning on the entire surface of the metal [11-14]. In addition to the degradation of ultimate strength, the reliability of randomly corroded structures has achieved a growing interest [15-19]. Being different from the general corrosion that uniformly attacks the whole surface of the metal and results in a smooth appearance, pitting corrosion is defined as a localized attack on the metal surface, confined to a point or small area that takes the form of cavities [6]. A universal method instead of modelling real features of pitting corrosion is to simplify corrosion pits into a corrosion patch with an equivalent uniform thickness reduction $[20,21]$. A more realistic alternative is to treat corrosion pits as circular cavities regularly (uniformly) or irregularly distributed over the surface [22-25]. Numerous studies 
on the influence of the pitting damage on the reduction of ultimate strength have been carried out $[26,27]$. In those studies, a specified pattern of pitting distribution was modelled for a certain level of pitting intensity. The pit shapes that should be of randomly varied sizes have been simplified into a circular cavity with an identical diameter [25]. And the random depths of pits, though they are the main feature to reflect the progress of pitting corrosion [28-31], have been modelled as a constant [24]. It is widely agreed that the pitting damage causes significant strength reduction, and the pitting distribution has much impact on the ultimate strength degradation [20, 32, 33]. However, there are few studies into the impact of random pitting corrosion on the ultimate strength and structural behaviour of the pitted structures $[6,9]$, despite the insights into structural reliability and collapse behaviour of the corroded structures duo to general corrosion [34-36].

Therefore, this paper aims to understand the failure mechanism of the plated steel structure due to the random pitting damage, and explore the degradation and variation of ultimate strength. A method based on stochastic simulation was developed and proposed to model the random pitting corrosion in situations with limited statistical data. The computing models were verified to replicate the pitted plated structures. A series of nonlinear analyses were performed to systematically investigate the correlation of ultimate strength reduction with pitting corrosion degradation. The mechanisms of structural failure were disclosed through illustrating the process of initiation and propagation of material plasticity due to the random pitting damage. The stochastic simulations were applied to explore the statistical characteristics of ultimate strengths resulting from the change in the pitting distribution.

\section{Computing Model of Pitted Structure}

Analysis of pitting corrosion on actual hull structures has shown that the shape of the pit on the 
hull plate is typically a circular cone while the distribution of the pits is scattered across the plate $[10,22]$. Although pitting corrosion has been studied for several decades, in-depth knowledge of pitting modelling is lacking [6]. In respect to the ultimate strength of pitted structures, using circular pits instead of modelling real pits is considered to be practical to simplify the modelling of the pitting corrosion [22]. Solid elements are considered to be more suitable for modelling detailed pits because of the capacity to describe the three-dimensional (3D) shape of the pit. Despite this, it is impossible to model the exact random 3D shape of real pits due to the complexity and randomness in the pitting morphology. Modelling a large number of 3D pits on a structural element is an time consuming task [33], but results in a limited difference in the calculated ultimate strength between $3 \mathrm{D}$ cones and $2 \mathrm{D}$ cylinders $[33,37]$. A set of pits modelled as circular indentations were thereby considered to be able to reflect the main statistical characteristics of random pitting corrosion relevant to pit depth and shape as well as pitting distribution [10]. Stochastic simulation was used to construct a model of a plate with random pitting damage. In the model, pitting features relevant to pitting shape, depth and distribution were addressed using three random variables. Model verification against the existing studies was performed in Section 2.2 and its applicability to accurately represent the pitted structure was discussed in Section 4.

\subsection{Modelling random pitting corrosion}

One stochastic feature in pitting corrosion is the shape of small hole in the metal due to extremely localized corrosion. The pitting shape is made up of its width (diameter), $w$, and depth, $d$, which forms a shape vector:

$$
\{S\}=\left\{\left(w_{1}, d_{1}\right),\left(w_{2}, d_{2}\right), \ldots,\left(w_{n}, d_{n}\right)\right\}^{T}
$$

where $\left(w_{i}, d_{i}\right)$ consists of the width and depth of $i^{\text {th }}$ pit, which can be simulated in terms of statistical 
features from the previously collected corrosion data [8]. The measured data from real ship structures show that the pit shape is generally circular and that the ratio of pit diameter to its depth is in the range of $8: 1$ to $10: 1$ for main hold frames in bulk carriers, and 4:1 to $6: 1$ for bottom shells in oil tankers $[26,28]$.

In some cases, several pits scattered close to each other may coalesce into a corrosion patch. However, the standard Pitting Intensity Diagrams in IACS specification [7] show that this is not serious for in-service structures under $25 \%$ pitting intensity. The equivalent volume loss of material is widely accepted to be the main factor in determining the ultimate strength reduction, and differences in pit shape have a negligible influence $[25,32]$. The coalition pits were considered to be one equivalent pit approximately shaped with an altered radius and depth but yielding the same volume loss of corroded material, replacing the pits with complex shapes for ease in generating a finite element (FE) mesh in the pitting area.

The other random feature of the pitting corrosion is the pitting distribution, represented by a position vector:

$$
\{P\}=\left\{\left(x_{1}, z_{1}\right),\left(x_{2}, z_{2}\right), \ldots,\left(x_{n}, z_{n}\right)\right\}^{T}
$$

where $\left(x_{i}, z_{i}\right)$ are the random coordinates, in axes, $x$ and $z$, of one pit on the structural surface.

Figure 1 shows the random nature of the modelled pitting in a sample plate between stiffeners subjected to an axial compressive load, which is a typical structural element in a stiffened plated structure. The width of the plate is taken as the reference direction, $x$ axis, and the $z$ axis is taken in the direction normal to the $x$ direction. The plate length and width are denoted by $a$ and $b$, respectively, and the plate thickness is $t$. The coordinates of points in the $x$ - $z$ plane referring to an intact plate can be used to represent the possible positions where pits may be located. In order to 
describe the location of pits in the pitted plate, the plate surface was divided into latticed grids with edge lengths approximately equal to $\eta r$, as shown in Figure 1. Here, $\eta$ is a shape coefficient that decides the length of the grid, and $r$ is the mean radius of circular pit. The pitted plate was then composed of three basic parts: the intact region, pit region and border region, as shown in Figure 1, with particular geometric properties in Table 1. Each grid point can hold one pit, and then the $x, z$ coordinates of the grid point represent the specific location of the pit. The partition of the plate with $M \times N$ grids by edge length of $\eta r$ yielded $(M+1) \times(N+1)$ possible positions, which were stored in a two-dimensional array with $M+1$ rows and $N+1$ columns. The random nature of the pitting distribution was simulated by randomly assigning the pits to the possible positions.

Pits were initiated at some of the grid points using a simple random number generator. The row and column numbers of the possible position to hold one pit was randomly determined. Since the pitted plate was divided into grids with a modular length of $\eta r$, the specific position of a single pit can be obtained through multiplying the numbers of row and column by the modulus, as follows:

$$
\begin{gathered}
\operatorname{pit}_{i} \sim \operatorname{pit}\left(x_{i}, z_{i}, r_{i}, d_{i}\right) ; i=1,2, \ldots, n \\
x_{i}=\eta r \times \operatorname{random}(2, M) ; i=1,2, \ldots, n \\
z_{i}=\eta r \times \operatorname{random}(2, N) ; i=1,2, \ldots, n
\end{gathered}
$$

where, $r_{i}$ and $d_{i}$ are the radius and depth, respectively, for $i^{\text {th }}$ pit, predetermined according to the statistical data measured during the structural surveys. The random pits can be assigned on any regions of the pitted plate.

It is critical for modelling pitting damage to address the randomly variable pit depth in the FE model because the pit depth is one of the main features of the random pitting corrosion. Essentially, the depths of the simulated pits in shape vector $\{S\}$ need to be associated with the areas in each FE model where the pits were randomly located. This was achieved by assigning a specific shell thickness for the area related to each pit. Since the pitted structure has been classified into three 
categories of typical regions according to their geometric properties, every pitting area within a classified region can be selected one by one to assign a particular thickness relevant to the shape vector $\{S\}$ using the algorithms in Table 1 . Figure 2 outlines the procedural steps to model the random pitting corrosion in a plated structure. A simulated plate with random pitting is shown in Figure 3 in comparison with a real one.

\subsection{Verifying computing model}

A square plate with dimensions of $800 \times 800 \times 10$ (unit: $\mathrm{mm}$; length $\times$ width $\times$ thickness), derived from Paik et al. [22], was used to validate the proposed modelling method. Two cases with different patterns of pitting distributions were adopted for the model validation. These included one with regularly distributed pits and another with irregularly distributed pits, all the pits of which perforates the plate thickness. The plates were simply supported on all four edges and subjected to a uniaxial compressive load, pits were shaped as cylindrical perforated indentations by SHELL181 in ANSYS, and other conditions not specially mentioned were consistent with Paik et al. [22]. In respect to regular pitting, comparisons between the FE results herein and Paik's results show good agreement under five levels of pitting intensities (DOPs, the percentage ratio of corroded area to intact area) shown in Figure 4(a). In the case of irregular pitting, model validations were performed under two levels of pitting intensities of DOPs $4.5 \%$ and $11.3 \%$ that result in the same percentage volume losses of material, respectively, $4.5 \%$ and $11.3 \%$, due to the pitting through the plate thickness. Owing to the difficulty to duplicate a specified distribution pattern exactly for the irregular pitting, stochastic simulations generated 100 plate models under each level of pitting intensity in order to include all these specified pitting patterns in [22]. In Paik et al.[22], the lower pitting intensity consisted of 29 pits with discrete diameters of $20,30,40$ and $50 \mathrm{~mm}$, while the 
higher one contained 43 pits with various diameters of 30, 40, 50 and $60 \mathrm{~mm}$. Figure 4(b) displays load-shortening curves of the plates at the two levels of pitting intensities. For each case with the irregular pitting, three curves corresponding to the maximum and minimum strengths as well as that closest to [22] are reported. Comparisons of these curves with the published results show excellent agreement, verifying the accuracy of the numerical models.

\section{Structural Assessment of Pitted Plate Structures}

Pitting damage on the plated steel structures operated in a corrosive environment was affected by a large scope of influential factors, likely resulting in much uncertainty in the structural system due to the limitation of the collected data used for evaluating ultimate strength. This section is to study the failure mechanisms and strength degradation in unstiffened plate and stiffened panel structures due to the random pitting damage.

Target structures to be analyzed included an unstiffened plate surrounded by stiffeners and transverse frames, and a panel with one stiffener and one span plating ( $\mathrm{a}^{1 / 2}$ plating either side), as shown in Table 2. The width of $b$ was $0.7 \mathrm{~m}$, the aspect ratio of $a / b$ was 3 , and the thickness ratio of plating to the width of $b / t$ was 7 . The adopted stiffener was an angle bar with $h_{w} \times b_{f} \times t_{w} \times t_{f}$ of $138 \times 90 \times 9 \times 12$ (unit: $\mathrm{mm} ; h_{w}$ and $t_{w}$ are height and thickness of web plate, respectively, and $b_{f}$ and $t_{f}$ are width and thickness of flange plate). The geometric and material properties of the target structures are listed in Table 2, and the ideal bilinear elastoplastic model was used throughout the nonlinear analysis. The boundary conditions of the models of the plate and panel structures were dependent on the support members connected to the target structures, as described in Table 3. For the unstiffened plate, the four plate edges were assumed to be simply supported owing to the stiffeners and transverse frames at the boundary. For the stiffened panels, symmetric boundaries 
were applied to the two edges of the plate, parallel to the stiffener, on the $(1 / 2+1 / 2)$ span plating, while simply support conditions were used for the other two edges of the plating and the two ends of the stiffener. A displacement along $z$ axis was applied on the simply supported end at $z=a$, where the displacement in $z$ axial direction was not constrained, mimicking a uniaxial compressive load. An initial deflection in the plating $\left(w_{p}\right)$ was introduced into the model of the plated structure, defined as Eq.(5). Two additional types of initial distortions, namely column type distortion of the stiffener $\left(w_{c}\right)$ and sideways distortion of stiffener $\left(w_{s}\right)$ [38], were considered in the panels. Figure 5 demonstrates the three types of initial geometric imperfections. Residual stress was not considered because of the primary purpose in this paper aiming at exploring the characteristics of strength reduction due to random pitting damage.

$$
\begin{gathered}
w_{p}=A_{0} \sin \left(\frac{m z}{a} \pi\right) \sin \left(\frac{x}{b} \pi\right) \\
w_{c}=B_{0} \sin \left(\frac{z}{a} \pi\right) \sin \left(\frac{x}{B} \pi\right) \\
w_{s}=C_{0} \frac{y}{h_{w}} \sin \left(\frac{z}{a} \pi\right)
\end{gathered}
$$

where $A_{0}=0.01 \beta^{2} t, \beta=b / t \sqrt{\sigma_{s} / E} ; m=$ buckling mode of the plate which is defined as a integer, herein, $m=a / b ; B$ is the width of whole panel; and $B_{0}=C_{0}=0.0015 a$.

The pitting corrosion introduced into the computing model was limited under DOP 25\%, in view of the range defined by the Classification Societies Rules [7, 39]. The pitting data originated from the measured data collected from the hold frames of 13 year old bulk carriers [8]. The depths of the adopted pitting data were considered to follow a Log-Normal distribution with standard deviation and mean value of 0.3 and 0.4 , respectively. The pit depths were randomly determined according to the statistical properties. Figure 6 shows the probability density of the pit depths of the simulated pits. The radius of every individual pit was defined by the ratio of pit diameter to pit depth, which randomly varies in the range from 8:1 to 10:1 with a uniformly distributed pseudo 
random number.

All the structures were modelled by four-node shell elements, SHELL181 in the FEA package ANSYS. One-sided pitting corrosion causes an impact to the structural strength more serious than the corrosion on the both side due to the extra bending in the pitting areas under axial compression $[27,40,41]$. The pits with one-sided corrosion were studied, and mid-plane nodes in pitting areas were moved to the bottom of the elements aligning with the intact surface. Convergence analysis on the mesh density was performed by comparing the calculated ultimate strength of plates between coarse and fine mesh schemes, respectively using 48 and 12 shell elements to represent one pit, as shown in Figure 7. The fine mesh models obtain more accurate results than the coarse one for various levels of pitting intensities but without consuming too much computing resource. In combination with the meshing pattern previously validated in Section 2.2, the mesh size adopted in the intact region was determined to be $t \times t$, and the fine mesh scheme was used throughout the nonlinear analysis in the following sections.

\subsection{Unstiffened plates}

Stochastic simulation was firstly applied to generate a large number of plate models with random pitting corrosion for the clarification of the correlation of strength reduction with the degree of pitting degradation. This necessitated sufficient simulations to cover a large range of pitting intensities from DOP $0 \%$ to DOP $25 \%$ in the range of IACS regulations. The number of simulations was empirically determined to be 1000 . The number of pits in each plate model was randomly determined using a uniformly distributed simple random number in a range of integers from 1 to 558. Figure 8 shows the relation between the resulting pitting degradation and the numbers of pits. The larger the number of pits, the more serious the corrosion degradation. In the simulated plate 
model, the load was applied to the edge $z=a$, and the average stress was calculated based on the reaction forces in the edge $z=0$. A plated structure was thought to reach the ultimate state in the loading process when the maximum average stress was achieved. The results of all the simulated plates at various levels of pitting intensities are shown in Figure 9. The ultimate strength of the intact plate was regarded as the standard strength $\sigma_{0}$ of $221 \mathrm{MPa}$. A non-dimensional strength factor $R_{S}$ of ultimate strength $\sigma_{u}$ was defined, as $R_{S}=\sigma_{u} / \sigma_{0}$, to reflect the ultimate strength of the pitted plate. Nonlinear analyses were also carried out on 50 plates subject to general (uniform) corrosion, as shown in Figure 9, to clarify the disparities between the strength degradations caused by the general (uniform) corrosion and random pitting corrosion.

The degree of degradation of the plate due to the pitting corrosion was represented by the corroded volume loss of material, defined as:

$$
D O V=\frac{V_{c}}{V_{0}} \times 100(\%)=\frac{\sum_{i=1}^{n} \pi r_{i}^{2} d_{i}}{a \times b \times t} \times 100(\%)=\frac{\pi}{a b} \sum_{i=1}^{n}\left(\frac{d_{i}}{t} r_{i}^{2}\right) \times 100(\%)
$$

where $V_{0}$ is the volume of the intact plate, and $V_{c}$ denotes the volume loss of material. Regression analysis was respectively performed on the FE results of the plates with the pitting corrosion and uniform corrosion. A power function was derived to express the ultimate strength factor due to the random pitting damage as:

$$
R_{S}=1-0.04749 \times D O V^{0.6459}
$$

The $R^{2}$ value of the empirical formula was evaluated as 0.93 , indicating a good fitting to the numerical results. In comparison, the ultimate strength factor of the plate with the uniform corrosion varied linearly as a function of the volume loss of material as:

$$
R_{S}=1-0.0019 \times D O V
$$

The $R^{2}$ value of 0.99 also shows a precise fitting of the regression function. 
The pitting damage results in a weakening in the structural stiffness of the plated structure even if at the elastic stage of overall structural deformation. Figure 10 illustrates mean stress-strain curves of the plates with the pitting damage at different levels of pitting intensities. In most cases, a pitted plate has a truncated curve due to structural failure, showing a lower ultimate strength and a different curve shape compared to the intact plate. For instance, the ultimate strength (179 MPa) of the pitted plate at DOP 25\%, denoted by ABCD in Figure 10, is about 20\% lower than that (221 $\mathrm{MPa}$ ) of the intact plate. The degradations in the capacities of loading and deforming are caused by the random pitting damage inducing excessive localized deformation in the pitting areas.

The most adverse effect of pitting damage lies in causing stress concentration and premature plasticity of structural material. This was demonstrated in the failure process of a sample plate at DOP $25 \%$ salvaged from Figure 10. Figure 11 clearly shows onset of plasticity and its propagation due to the random pitting damage, corresponding to the points labeled by A, B, C, and D in the load-shortening curve. The plasticity initiates at the corrosion pits situated close to one of the two unloaded edges of the plate shown in Figure 11(a), and propagates towards the plate center as the progress exhibited from Figure 11(b) to (c). This forms a continuous plasticity region transversely throughout the both unloaded edges illustrated in Figure 11(d).

The larger stress concentration, plotted in Figure 11, shows a tendency to occur near the pits in the direction normal to the unloaded edges, under uniaxial longitudinal compression, as observed in $[24,42]$. The interaction between boundary effect and the stress concentration causes the early onset of plasticity to initiate easily close to the unloaded edge. The propagation of the plasticity depends on the stress fields around the neighboring pits, which produces a plasticity path connecting the higher stress regions between the neighboring pits. Notably, the process of the plasticity 
proliferation shown in Figure 11, corresponding to the load-shortening curve at DOP 25\% in Figure 10 , reveals that the pitting damage has a detrimental effect on the structural behavior. It is evident that the plasticity has initiated in areas shown in Figure 11(a) and (b) where the corrosion pits were situated, even if the entire structure displays an elastic deforming illustrated by the intercepted curve A-B in Figure 10.

The early onset of the plasticity due to the pitting damage amplifies local deformation and results in structural failure, as shown in Figure 12. Before the structure collapses, the deformations in the intact and pitted structures take almost the same shape as the initial deflection in the form of three half-sine waves. In the intact plate, the deformations of all the three half-sine waves develop simultaneously continuously with the initial shape until structural failure, as shown in Figure 12(a). But the situation is completely different in the pitted plates , asynchronous deformations develop in those half-waves due to the scattered corrosion pits, as shown in Figure 12(b) (d), with a locally amplified amplitude within one single half-sine wave. The early onset of the plasticity results in structural failure illustrated in Figure 12(d).

The random nature of pitting distribution causes significant variation in the ultimate strength of the pitted structure. Additional stochastic simulations were performed to simulate 200 pitted plates for the investigation of statistical characteristics of ultimate strength under each of four levels of pitting intensities accounting for the change of pitting distribution. Convergence of the stochastic simulation was verified on the mean value of ultimate strength from the 200 simulations, shown in Table 4; displaying a good robustness at each level of pitting intensity. Table 5 summarizes the statistical properties of ultimate strength under various pitting intensities, showing that the higher the pitting level, the lower the mean ultimate strength. A Chi-square test performed shows that the 
probabilistic distribution of ultimate strengths appears to follow a normal distribution as shown in Figure 13(a) - (b) under DOP 15\%, despite the ultimate strength considerably varied due to the change of the pitting distribution. However, for the higher levels of pitting intensities over DOP $20 \%$, the normal distribution does not fit so clearly to the probabilistic ultimate strength in Figure 13(c) - (d). Overall, small differences in standard deviations of ultimate strength between various levels of pitting intensities, shown in Table 5, imply a limited correlation between the strength variation and the level of pitting intensity. The reduction of ultimate strength increases with increase of the level of pitting degradation, with a decreasing mean strength that engenders a slightly larger Coefficient of Variation (COV) due to an almost identical standard deviation. It is believed that the reduction of ultimate strength caused by the pitting damage is closely related to the interaction between structural parameters, such as plate slenderness and aspect ratio, and the level of pitting intensity [24]. The stable standard deviations indicate that these structural parameters play a vital role to resist the change of pitting distribution.

Although the higher level of pitting intensity the smaller mean value of ultimate strength, as indicated in Table 5, the strength reduction at a higher level of pitting intensity is not always more than that at a lower one. A lower pitting case likely leads to more reduction of ultimate strength compared with a higher pitting case, even resulting in a strength smaller than the mean strength of the latter. For instance, the lowest strength, $174 \mathrm{MPa}$, for DOP $20 \%$ is less than the mean strength, $176 \mathrm{MPa}$, for DOP $25 \%$. Thus, a high risk of structural safety may result from the specified pitting distribution without taking into account the random nature of the pitting corrosion, as the worst case causing the lowest strength may be beyond the pitting patterns that were subjectively determined. 


\subsection{Stiffened Panels}

Stochastic simulations were also performed on stiffened panels with pitting damage to study the pitting impact on structural performance of larger components. The pitting on the stiffener of panel was not taken into account in this study. As before, the relationship between the strength reduction and the degree of pitting degradation was firstly studied upon 1000 simulations to ensure sufficient data, and the analysis on the statistical characteristics utilized 200 stochastic simulations for each of four levels of pitting intensities (DOPs 10\%, 15\%, 20\% and 25\%). The regression formula with respect to the strength decrease and material loss was defined as Eq.(9) based on the simulations.

$$
R_{S}=1-0.01949 \times D O V^{0.8346}
$$

The $R^{2}$ value of 0.92 also indicates an accurate fit between the regression function and the FE results.

Convergence of the stochastic simulations was also verified for each level of pitting intensity, as shown in Table 4, displaying an excellent robustness over the 200 simulations. Figure 14 plots membrane stress, plastic strain and post-collapse mode of a sample panel with pitting corrosion at DOP $25 \%$, in contrast to the intact panel with the ultimate strength of $252 \mathrm{MPa}$. It is evident that the pitting damage has a serious influence on the distributions of stress and plastic strain in addition to stress concentrations, making the fields of stress and strain quite irregular. The pitted panel collapses with an amplified local deformation of plating resulting from the intensive highly stress-concentrated pits, as shown in Figure 14(b), which causes the onset and propagation of material plasticity, similar to the pitted plates. Also the amplified deformation in the local regions elicits a change in the post-collapse mode, where the pitted panel fails at the side half-sine wave 
while the intact panel collapses at the middle half-sine wave.

The results of Chi-square test show that the probabilistic distribution of the ultimate strengths of the pitted panels follow normal distributions under all the four levels of pitting intensities. Figure 15 shows the statistical properties of the ultimate strengths. In addition, Table 5 demonstrates that the changes in the pitting distributions cause a less variation in the stiffened panels at a certain level of pitting intensity, compared to the pitted plates, because the COVs in the pitted panels are always smaller, with $0.0568,0.0634,0.0781$ and 0.0703 , respectively, for the four levels of pitting intensities. The stiffened panels are thus less sensitive to the change of the pitting distribution than the unstiffened plates. The resistance to the pitting impact is because the stiffeners carry a large part of the compressive load in the pitted panels. Especially, at the highest level of the pitting intensity (DOP 25\%), the stiffener improves the ultimate strength up to $9.71 \%$ more than that of the unstiffened plate as Table 5 indicates.

\section{Discussion}

The ultimate strength reduction and structural behaviour of plated steel structures have been evaluated to understand the impact of random pitting corrosion. The regression formulae that can accurately predict the mean values of the ultimate strengths of the pitted structures are derived from the stochastic simulations, as show in Figure 16, and the results yielded by these formulae are compared with the results obtained from experiments [22] and existing empirical formulae [32, 43]. The formula related to the pitted plate can provide accurate, through slightly lower, predictions to the ultimate strengths of the experimental plates with artificial pitting damage [22]. The slightly higher strength of the experiment can be attributed to the idealization in the pitting morphology introduced into the test specimens. In the experiments, the random pits were simplified into 
perforated holes with uniform size regularly distributed with the same distance between individual pits. As a result of this, the regular pits result in a structural response with regularly distributed plastic strains and membrane stresses illustrated in Figure 17(a). In contrast, a highly irregular strain and stress field exists in the structure with random pitting damage, due to interference between the nearby pits with concentrated stresses, as shown in Figure 17(b). Notably, the random pitting leads to structural collapse in a mode completely different from the plates with the regular pitting, resulting in a ultimate strength (178 $\mathrm{MPa}$ ) about $7.7 \%$ lower than that (193 $\mathrm{MPa}$ ) with the regular pitting.

The random pitting damage causes significant degradation to the capacity of loading and deformation in the pitted structure concurrent with a great variation in the structural strength. The methods on the basis of uniform (equivalent) thickness reduction cannot account for the effect of the random pitting damage properly and often underestimate the reduction of ultimate strength, as shown in Figure 16. A plate with the random pitting at DOP 25\% (DOV 8.87\%) has a lower ultimate strength factor $\left(R_{s}=0.797\right)$. However, unduly optimistic results are produced by the methods in terms of uniform thickness reduction $\left(R_{s}=0.983\right)$ and Faulkner's equation [43] $\left(R_{s}=\right.$ 0.928), which are respectively about $23.3 \%$ and $16.4 \%$ higher than that of the random pitting. It is therefore not enough to assess ultimate strength of the pitted structure only based on a certain specified pitting pattern, especially, using a uniformly distributed pattern.

In this paper, the simulated random pitting complied with a Log-Normal distribution in terms of the actual pitting data collected from the renewed hold frames of the bulk carrier [8], within the levels of pitting intensities in the range of IACS regulations. At the highest level of pitting intensity of DOP $25 \%, 558$ simulated random pits resulted in the degree of pitting degradation of DOV 
$8.87 \%$, as shown in Figure 8 . The pitting scenario simulated depends on the representation of the statistical properties of pitting corrosion [44]. In Silva's work, a non-uniform corrosion model was applied to address the corrosion on the plate using rectangular shell elements with a varying thickness, leading to a corroded surface corresponding to that expected in more aggressive environments [32]. The formula derived from this non-uniform corrosion model provides an unduly pessimistic prediction in the residual strength not only for the simulated plates with random pitting damage but for the tested plates with though-thickness pitting [22], as shown in Figure 16. The probabilistic distribution of the actual pitting corrosion is time-variant with the progress of corrosion, likely varying from an exponential distribution to a normal distribution [28]. There are various probabilistic models to mathematically describe the distribution of pit depth $[29,30]$, but the impact on structural behaviour and strength reduction accounting for the different models remains unclear. This deserves further investigations, which can be fulfilled on the basis of the proposed modelling method in this paper.

\section{Conclusion}

A modelling approach has been proposed to simulate random pitting corrosion for structural assessment of corroded plated structure. A series of numerical analyses have been conducted on unstiffened and stiffened plated steel structures with pitting damage under a uniaxial compressive load, in order to systematically study strength reduction and structural failure mechanisms. The pitted structure collapses due to an amplified local deformation caused by the pitting damage, which induces material plasticity to initiate at the unload edge of the structures and to propagate towards the plate center. The structural failure mode is dominated by a continuous plasticity region linking the pits with higher levels of concentrated stress together. The random pitting corrosion causes a 
significant strength reduction and variation, and even changes structural failure mode.

\section{ACKNOWLEDGEMENTS}

This work was supported by Natural Science Foundation of Jiangsu Province of China [grant number BK2011507, BK20151326], Ministry of Construction Science and Technology Project of China [grant number 2016-K5-048], and the sponsorship of Jiangsu Overseas Research \& Training Program for University Prominent Young \& Middle-aged Teachers and Presidents. The author gratefully appreciated these supports.

The authors would like to thank Professor Nigel White from Lloyd's Register and Dr. Yikun Wang from the University of Southampton for their helpful suggestions and comments on the contents of this paper.

\section{REFEERENCE}

[1] S. Zhang, A review and study on ultimate strength of steel plates and stiffened panels in axial compression, Ships and Offshore Structures, 11 (2016) 81-91.

[2] M. Rahman, Y. Okui, T. Shoji, M. Komuro, Probabilistic ultimate buckling strength of stiffened plates, considering thick and high-performance steel, J Constr Steel Res, 138 (2017) 184-195.

[3] I.A. Chaves, R.E. Melchers, Extreme value analysis for assessing structural reliability of welded offshore steel structures, Struct Saf, 50 (2014) 9-15.

[4] T. Kaita, J.M.R.S. Appuhamy, K. Itogawa, M. Ohga, K. Fujii, Experimental study on remaining strength estimation of corroded wide steel plates under tensile force, Procedia Engineering, 14 (2011) 2707-2713.

[5] Y. Garbatov, C. Guedes Soares, J. Parunov, J. Kodvanj, Tensile strength assessment of corroded small scale specimens, Corros Sci, 85 (2014) 296-303.

[6] J. Bhandari, F. Khan, R. Abbassi, V. Garaniya, R. Ojeda, Modelling of pitting corrosion in marine and offshore steel structures - A technical review, J Loss Prevent Proc, 37 (2015) 39-62.

[7] IACS, Requirements concerning SURVEY AND CERTIFICATION, in, International Association of Classification Societies, London, 2016.

[8] N. Yamamoto, Probabilistic model of pitting corrosion and the simulation of pitted corroded condition, in: ASME 27th International Conference on Offshore Mechanics and Arctic Engineering, Estoril, Portugal, 2008, pp. 527-534.

[9] Y. Wang, J.A. Wharton, R.A. Shenoi, Ultimate strength analysis of aged steel-plated structures exposed to marine corrosion damage: A review, Corros Sci, 86 (2014) 42-60.

[10] J.C. Daidola, J. Parente, I.R. Orisamolu, K.T. Ma, Residual strength assessment of pitted plate panels, in, U.S. Coast Guard (G-MMS/SSC), Washington, D.C., 1997.

[11] Â.P. Teixeira, C.G. Soares, Ultimate strength of plates with random fields of corrosion, Structure and Infrastructure Engineering, 
4 (2008) 363-370.

[12] S. Saad-Eldeen, Y. Garbatov, C. Guedes Soares, Effect of corrosion severity on the ultimate strength of a steel box girder, Eng Struct, 49 (2013) 560-571.

[13] M. Reza Khedmati, Z.H.M.E. Nouri, Analytical simulation of nonlinear elastic-plastic average stress-average strain relationships for un-corroded/both-sides randomly corroded steel plates under uniaxial compression, Thin Wall Struct, 86 (2015) $132-141$.

[14] J. Guo, G. Wang, L. Ivanov, A.N. Perakis, Time-varying ultimate strength of aging tanker deck plate considering corrosion effect, Marine Structures, 21 (2008) 402-419.

[15] P.H. Wirsching, J. Ferensic, A. Thayamballi, Reliability with respect to ultimate strength of a corroding ship hull, Marine Structures, 10 (1997) 501-518.

[16] C.G. Soares, Y. Garbatov, Reliability of maintained, corrosion protected plates subjected to non-linear corrosion and compressive loads, Marine Structures, 12 (1999) 425-445.

[17] G. Wang, A.-K. Lee, L. Ivanov, T.J. Lynch, C. Serratella, R. Basu, A statistical investigation of time-variant hull girder strength of aging ships and coating life, Marine Structures, 21 (2008) 240-256.

[18] J. Guo, G. Wang, A.N. Perakis, L. Ivanov, A study on reliability-based inspection planning - Application to deck plate thickness measurement of aging tankers, Marine Structures, 25 (2012) 85-106.

[19] J.E. Silva, Y. Garbatov, C. Guedes Soares, Reliability assessment of a steel plate subjected to distributed and localized corrosion wastage, Eng Struct, 59 (2014) 13-20.

[20] D. Ok, Y. Pu, A. Incecik, Computation of ultimate strength of locally corroded unstiffened plates under uniaxial compression, Marine Structures, 20 (2007) 100-114.

[21] T.E. Dunbar, N. Pegg, F. Taheri, L. Jiang, A computational investigation of the effects of localized corrosion on plates and stiffened panels, Marine Structures, 17 (2004) 385-402.

[22] J.K. Paik, J.M. Lee, M.J. Ko, Ultimate compressive strength of plate elements with pit corrosion wastage, Journal of Engineering for the Maritime Environment, 217 (2003) 185-200.

[23] X. Jiang, C. Guedes Soares, A closed form formula to predict the ultimate capacity of pitted mild steel plate under biaxial compression, Thin Wall Struct, 59 (2012) 27-34.

[24] S. Sultana, Y. Wang, A.J. Sobey, J.A. Wharton, R.A. Shenoi, Influence of corrosion on the ultimate compressive strength of steel plates and stiffened panels, Thin Wall Struct, 96 (2015) 95-104.

[25] Y. Zhang, Y. Huang, F. Meng, Ultimate strength of hull structural stiffened plate with pitting corrosion damage under unaxial compression, Marine Structures, 56 (2017) 117-136.

[26] T. Nakai, H. Matsushita, N. Yamamoto, H. Arai, Effect of pitting corrosion on local strength of hold frames of bulk carriers (1st report), Marine Structures, 17 (2004) 403-432.

[27] X. Jiang, C. Guedes Soares, Ultimate capacity of rectangular plates with partial depth pits under uniaxial loads, Marine Structures, 26 (2012) 27-41.

[28] N. Yamamoto, K. Ikegami, A study on the degradation of coating and corrosion of ship's hull based on the probabilistic approach, J. Offshore Mech. Arct. Eng., 120 (1998) 121-128.

[29] R.E. Melchers, R.J. Jeffrey, Probabilistic models for steel corrosion loss and pitting of marine infrastructure, Reliab Eng Syst Safe, 93 (2008) 423-432.

[30] J.K. Paik, D.K. Kim, Advanced method for the development of an empirical model to predict time-dependent corrosion wastage, Corros Sci, 63 (2012) 51-58.

[31] S. Qin, W. Cui, Effect of corrosion models on the time-dependent reliability of steel plated elements, Marine Structures, 16 (2003) 15-34.

[32] J.E. Silva, Y. Garbatov, C. Guedes Soares, Ultimate strength assessment of rectangular steel plates subjected to a random localised corrosion degradation, Eng Struct, 52 (2013) 295-305. 
[33] T. Nakai, H. Matsushita, N. Yamamoto, Effect of pitting corrosion on the ultimate strength of steel plates subjected to in-plane compression and bending, J. Mar. Sci. Technol., 11 (2006) 52-64.

[34] A. Rahbar-Ranji, Ultimate strength of corroded steel plates with irregular surfaces under in-plane compression, Ocean Eng, 54 (2012) 261-269.

[35] S. Saad-Eldeen, Y. Garbatov, C. Guedes Soares, Strength assessment of a severely corroded box girder subjected to bending moment, J Constr Steel Res, 92 (2014) 90-102.

[36] A. Rahbar Ranji, Buckling analysis of corroded angle beams with irregular random surfaces, J. Fail. Anal. Prev., 16 (2016) 912-918.

[37] Y. Huang, Y. Zhang, G. Liu, Q. Zhang, Ultimate strength assessment of hull structural plate with pitting corrosion damnification under biaxial compression, Ocean Eng, 37 (2010) 1503-1512.

[38] S. Zhang, I. Khan, Buckling and ultimate capability of plates and stiffened panels in axial compression, Marine Structures, 22 (2009) 791-808.

[39] IACS, Requirements concerning STRENGTH OF SHIPS, in, International Association of Classification Societies, London, 2016.

[40] T. Nakai, H. Matsushita, N. Yamamoto, Effect of pitting corrosion on strength of web plates subjected to patch loading, Thin Wall Struct, 44 (2006) 10-19.

[41] Y. Zhang, Y. Huang, Q. Zhang, G. Liu, Ultimate strength of hull structural plate with pitting corrosion damnification under combined loading, Ocean Eng, 116 (2016) 273-285.

[42] Y. Wang, J.A. Wharton, R.A. Shenoi, Influence of localized pit distribution and bench-shaped pits on the ultimate compressive strength of steel plating for shipping, Corrosion, 70 (2014) 915-927.

[43] D. Faulkner, A review of effective plating for use in the analysis of stiffened plating in bending and compression, J Ship Res, 19 (1975) 1-17.

[44] R.E. Melchers, The effect of corrosion on the structural reliability of steel offshore structures, Corros Sci, 47 (2005) $2391-2410$.

[45] DNV, DNV Guidlines 10: Guide for ultrasonic thickness measurements of ships classed with Det Norske Veritas, in, 2009. 


\section{List of Figures and Tables}

Figure 1 Pitted plate partitioned by grids with length of $\eta \mathrm{r}$

Figure 2 Flow chart to model random pitting corrosion

Figure 3 Plated structure with random pitting corrosion

Figure 4 Validation of computing models subject to regularly or irregularly distributed pitting corrosion

Figure 5 Initial imperfection of a stiffened panel

Figure 6 Probability distribution of pit depths of simualted random pits

Figure 7 Relative error of ultimate strengths of plates with coarse and fine meshes

Figure 8 Relationship between degree of pitting degradation and number of pits

Figure 9 Relationship between ultimate strength reduction and volume loss of material

Figure 10 Mean stress-strain curves of sample pitted plates with random pitting damage

Figure 11 Onset and propagation of plastic strain in a sample plate due to randomly distributed pitting damage (DOP 25\%)

Figure 12 Contour plots of plastic strain (top) and post-collapse mode (bottom) of sample plates

Figure 13 Statistical distribution of ultimate strengths of pitted plates under uniaxial compression

Figure 14 Contour plots of membrane stress (top), plastic strain (bottom) and post-collapse mode

Figure 15 Statistical distribution of ultimate strength of pitted panels under uniaxial compression

Figure 16 Comparisons of ultimate strength factor between regression formula and existing studies

Figure 17 Contour plots of plastic strain (top), post-collapse mode (middle) and membrane stress (bottom; MPa) of plates with DOP $25 \%$ at ultimate state

Table 1 Meshing algorithms for classified plate with random pitting

Table 2 Geometric and material properties of plated structures

Table 3 Boundary conditions of plated structures

Table 4 Convergence analysis of stochastic simulation on mean value of ultimate strength (MPa)

Table 5 Statistical properties of ultimate strengths (MPa) at various levels of pitting intensities 


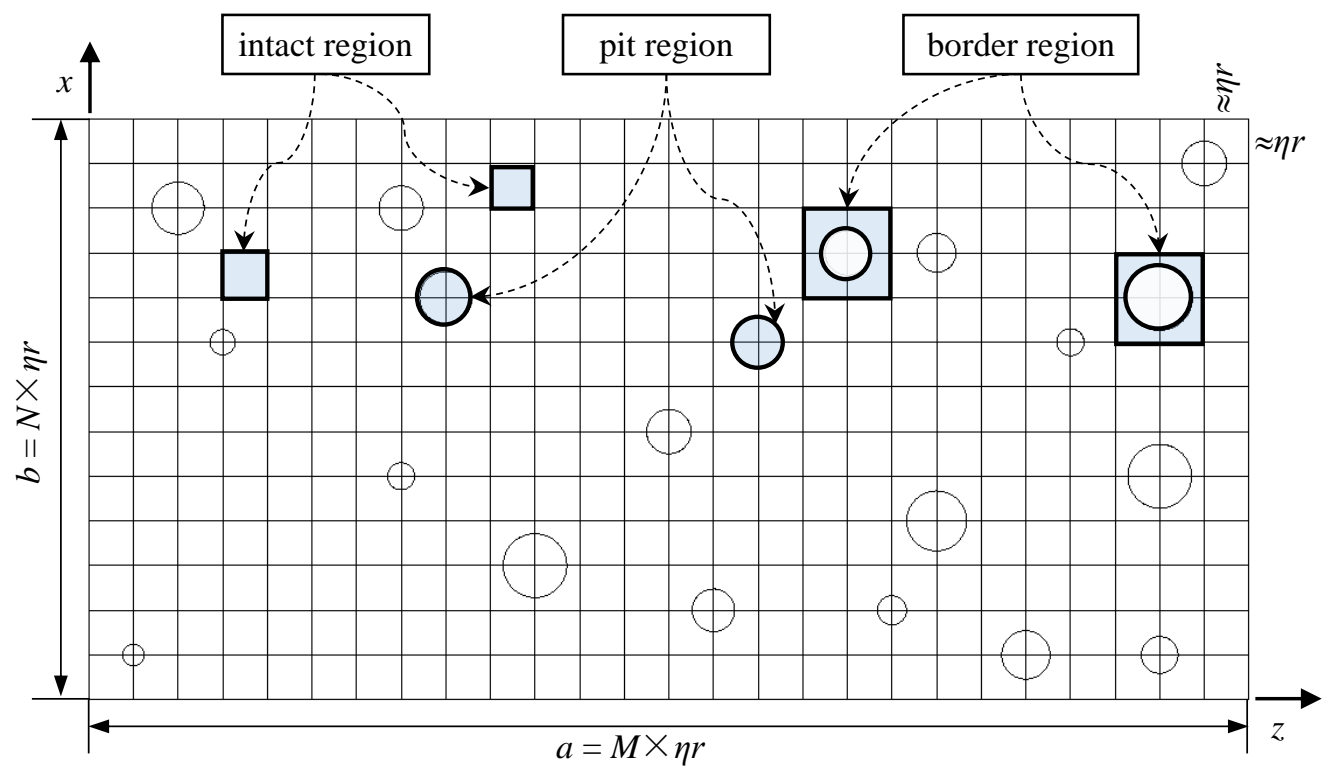

Figure 1 Pitted plate partitioned by grids with length of $\eta r$

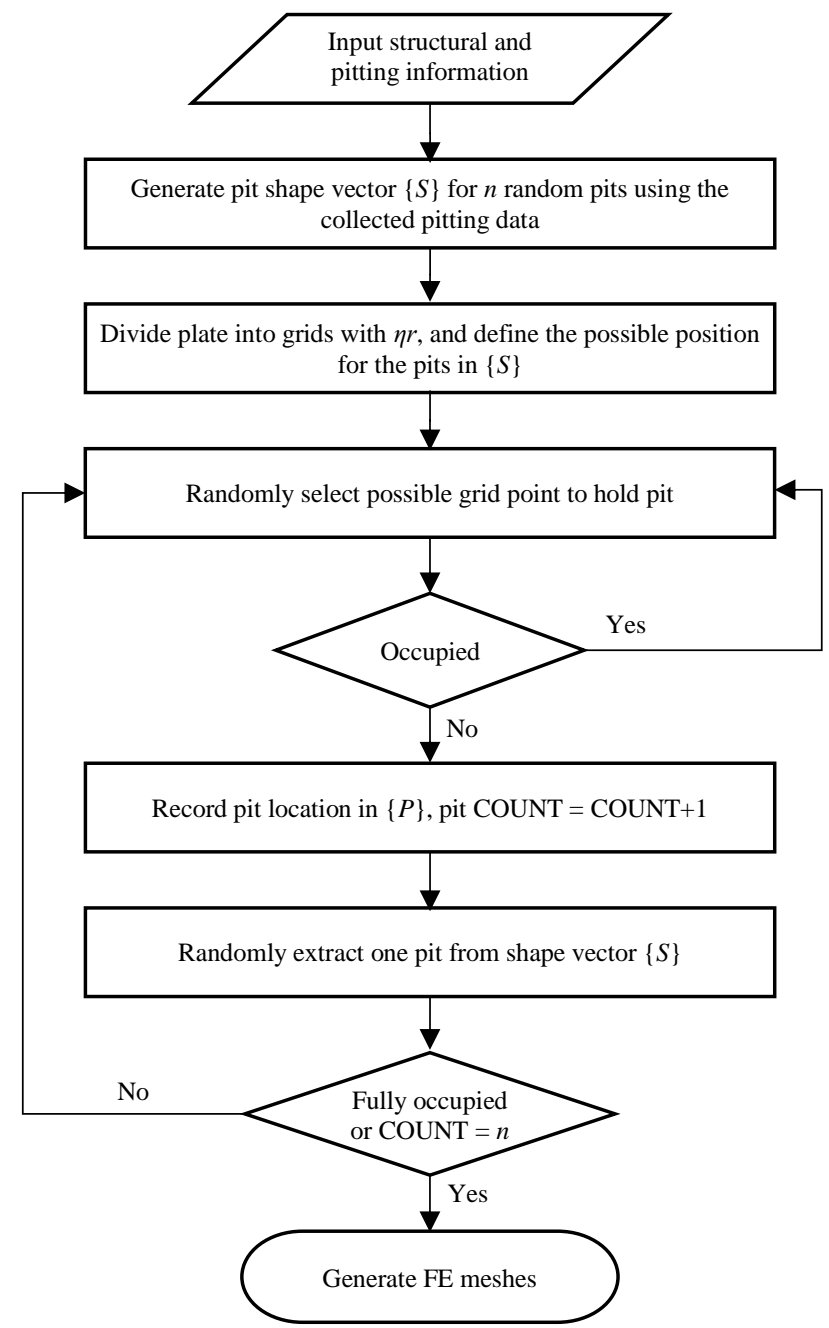

Figure 2 Flow chart to model random pitting corrosion 
(a)

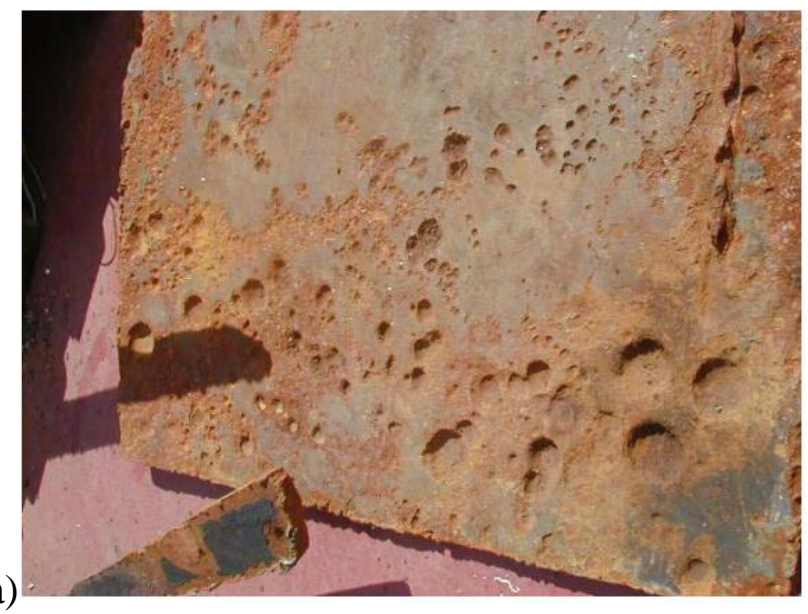

(b)

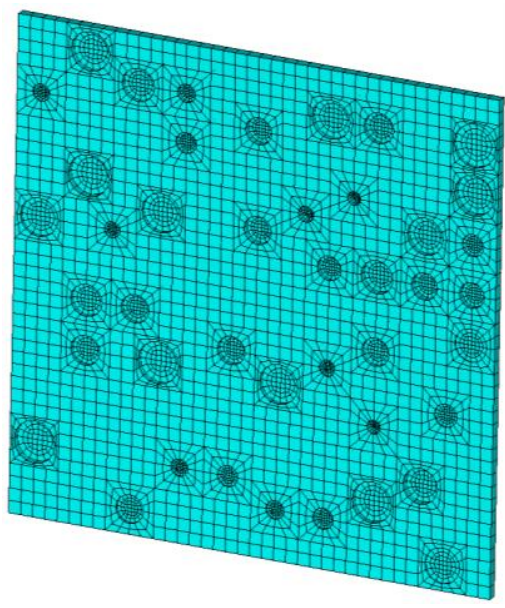

Figure 3 Plated structure with random pitting corrosion. (a): real pitted plate [45]; (b): simulated pitted plate

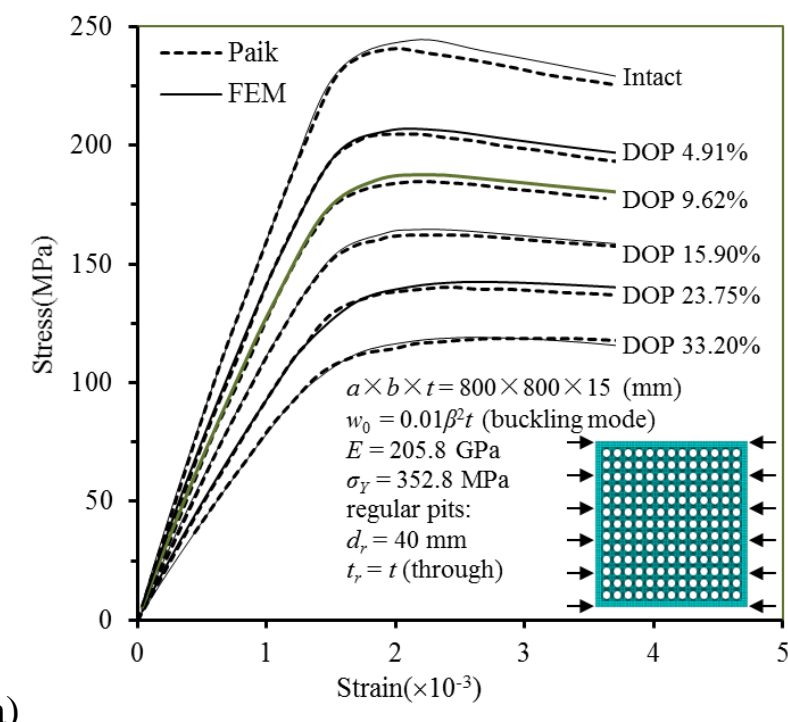

(b)

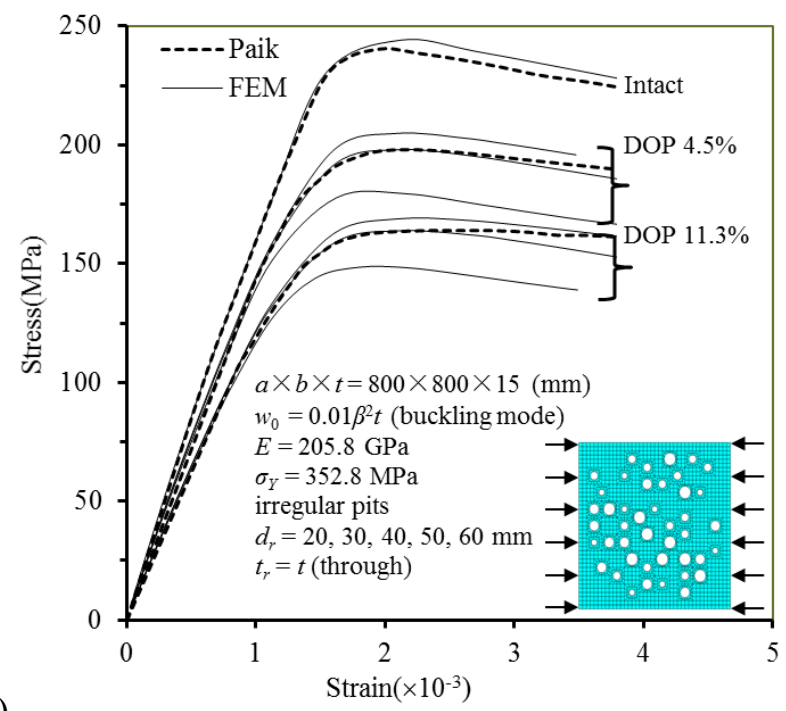

Figure 4 Validation of computing models subject to regularly or irregularly distributed pitting corrosion (through-thickness). (a): regular pits; (b): irregular pits 

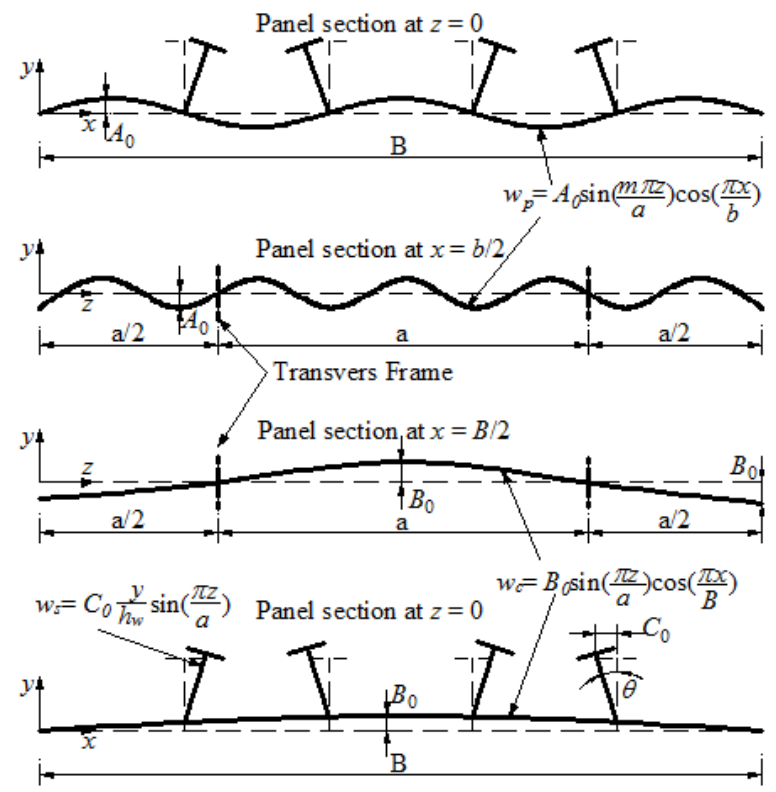

Figure 5 Initial imperfection of a stiffened panel

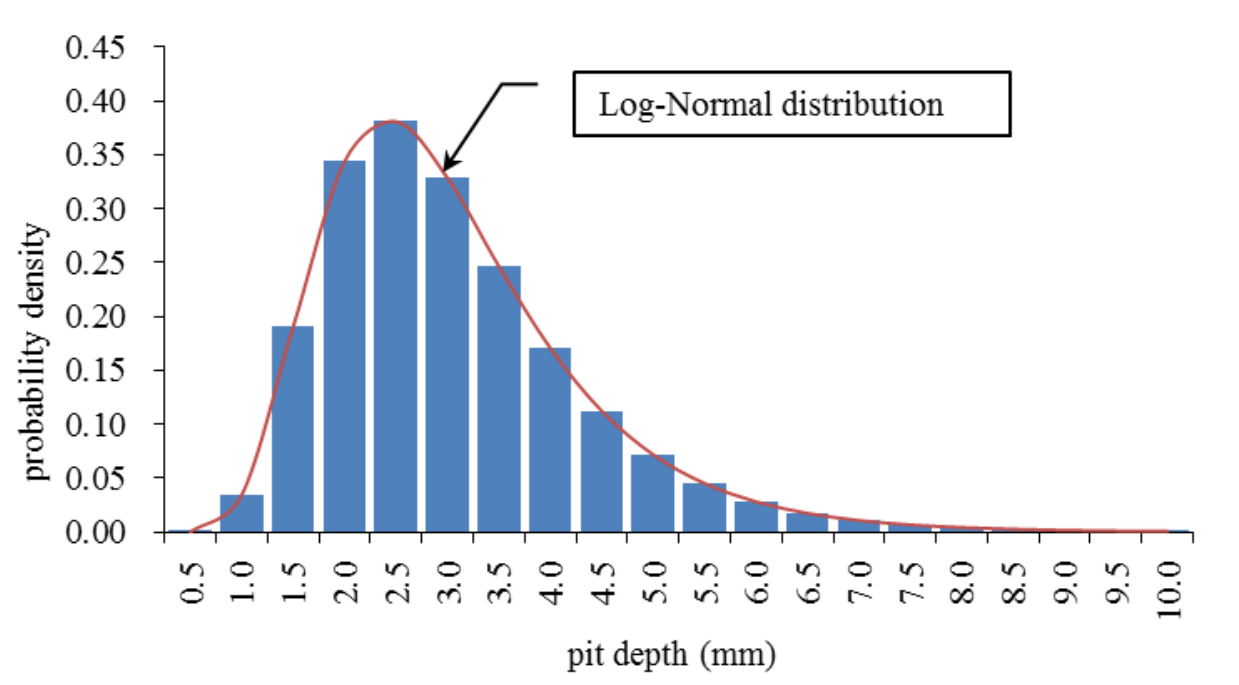

Figure 6 Probability distribution of pit depths of simulated random pits

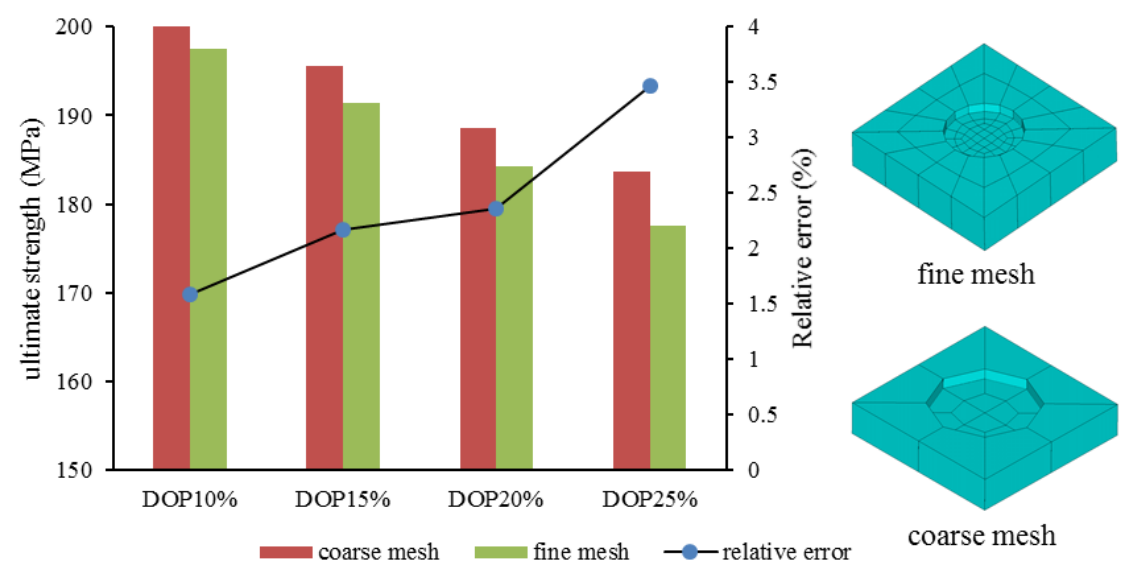

Figure 7 Relative error of ultimate strengths of plates with coarse and fine meshes 


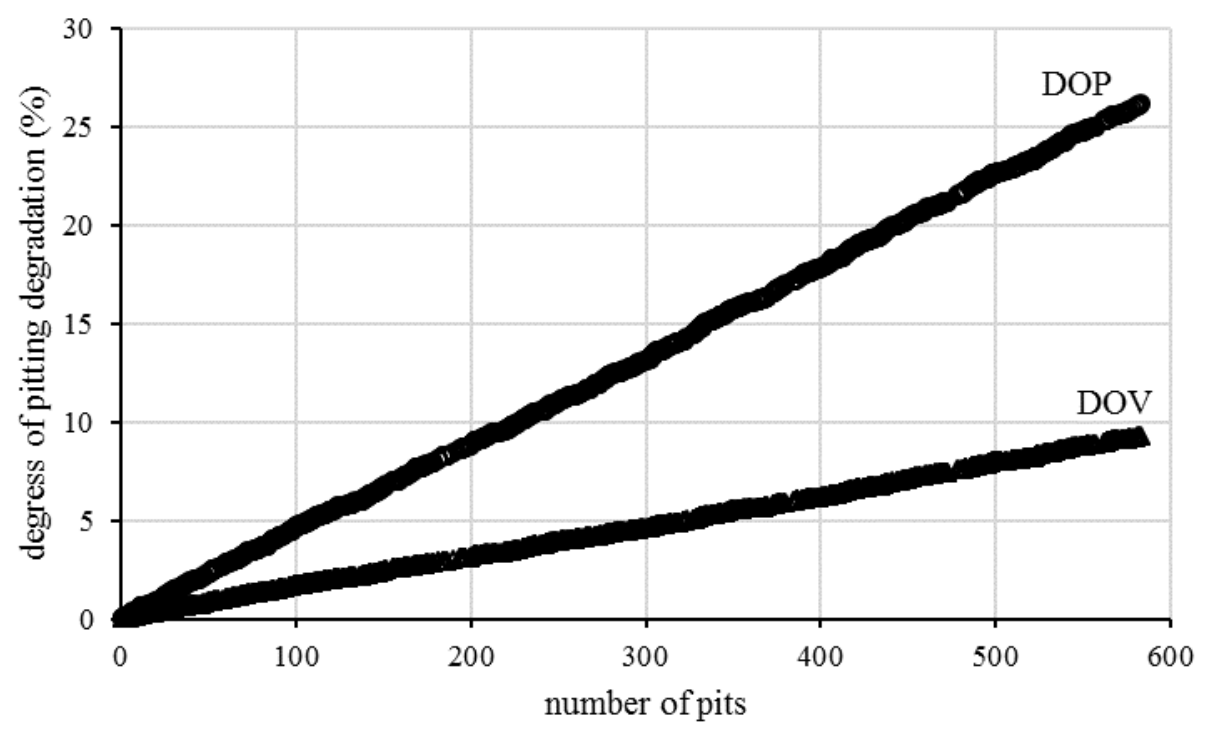

Figure 8 Relationship between degree of pitting degradation and number of pits

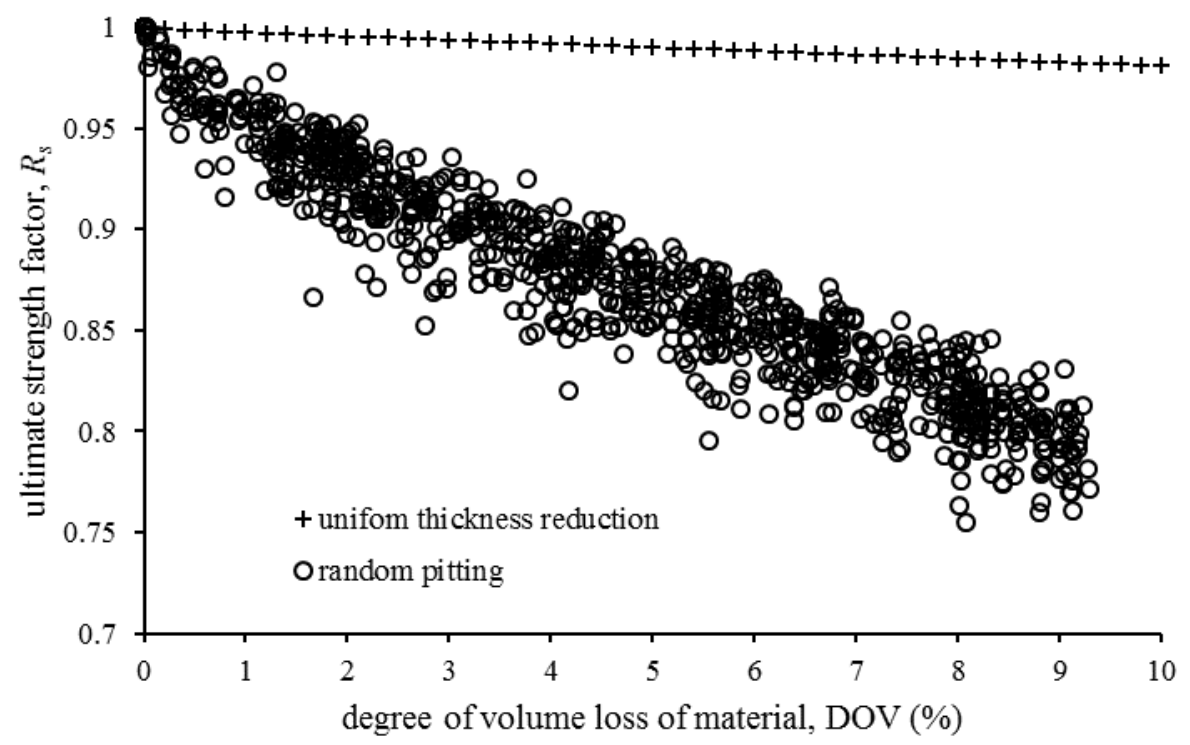

Figure 9 Relationship between ultimate strength reduction and volume loss of material 


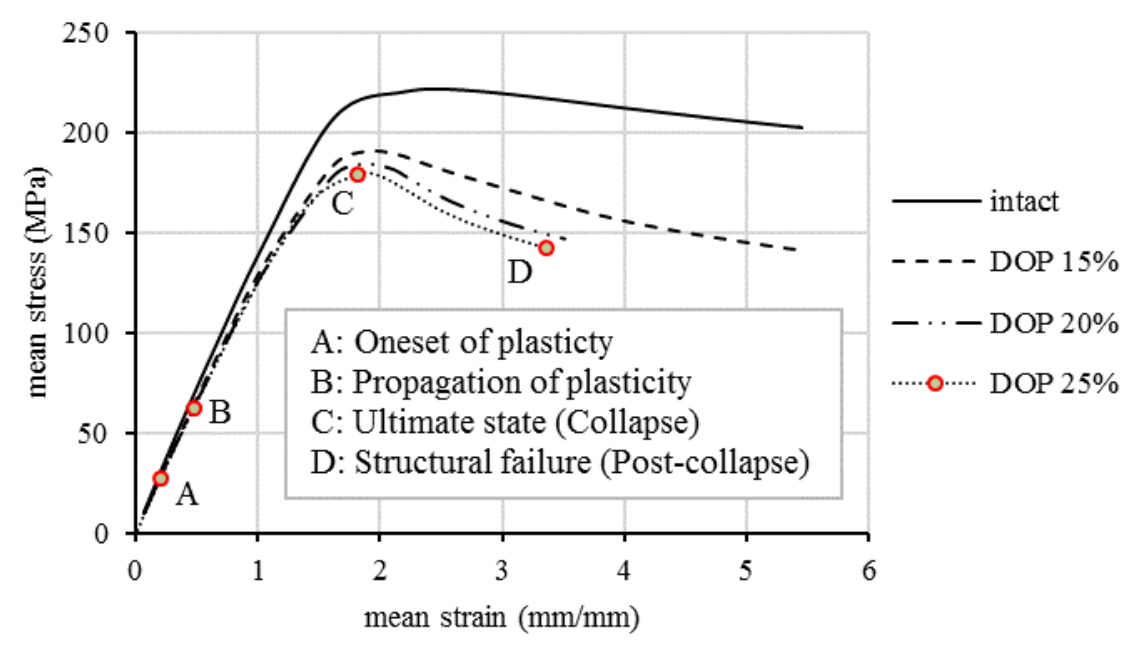

Figure 10 Mean stress- mean strain curves of sample pitted plates with random pitting damage

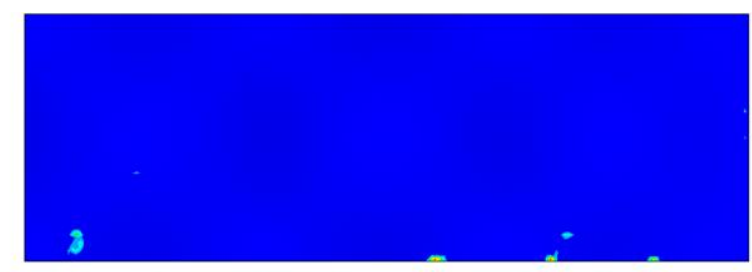

(a)

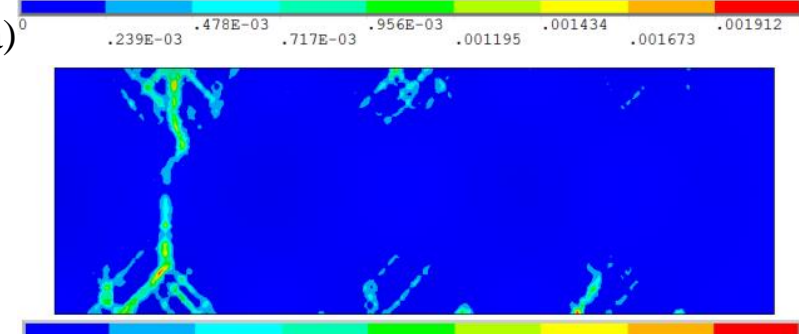

(c)

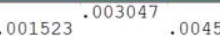

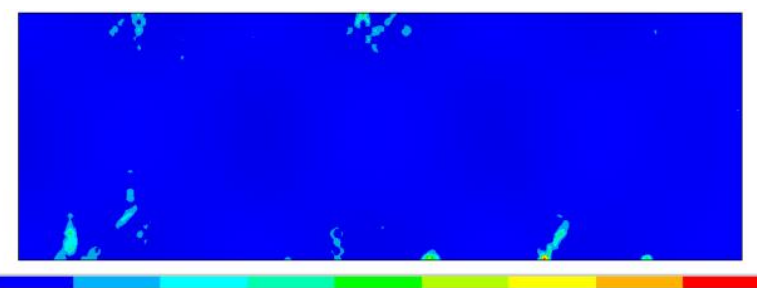

(b)

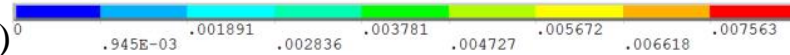

(d)

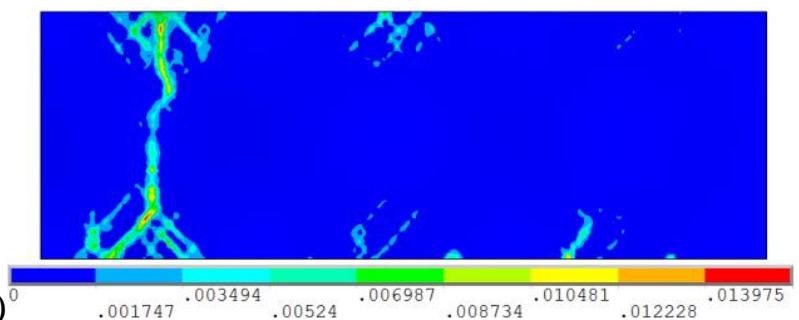

Figure 11 Onset and propagation of plastic strain in a sample plate due to randomly distributed pitting damage (DOP 25\%). (a): onset of plasticity (point A); (b): propagation of plasticity (point B); (c): structural collapse (point C); (d): structural failure (point D) 
(a)
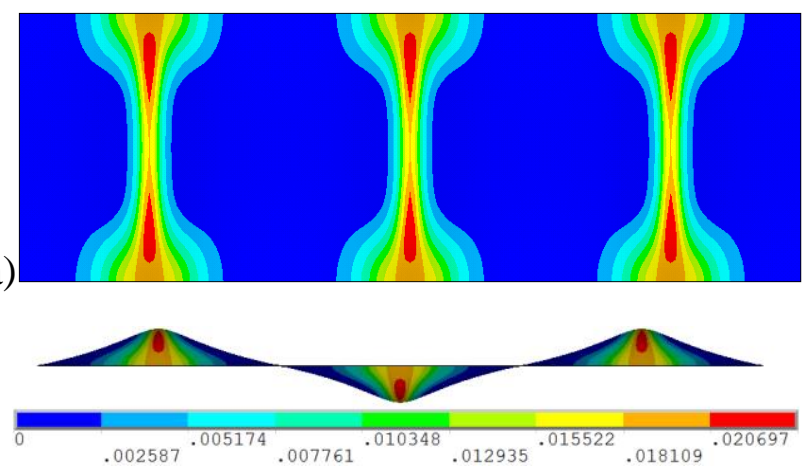

(c)

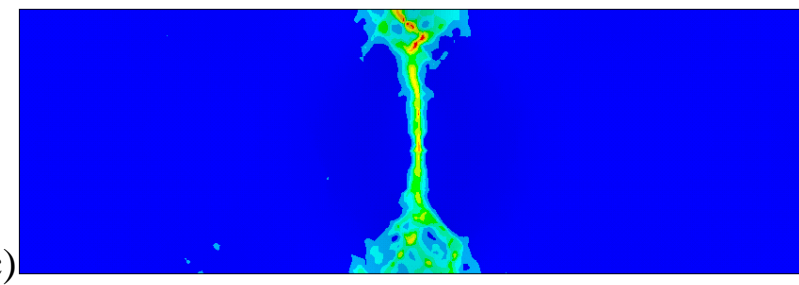

(d)

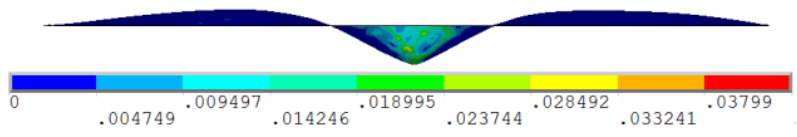

(b)
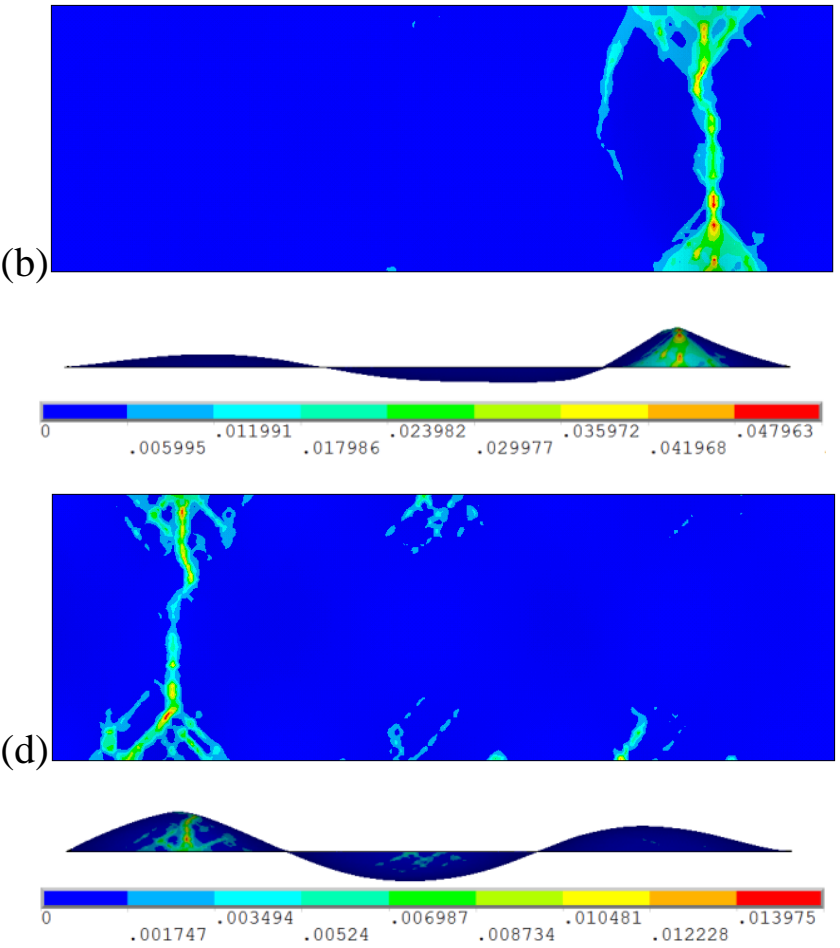

Figure 12 Contour plots of plastic strain (top) and post-collapse mode (bottom) of sample plates. (a): intact plate; (b): plate at DOP 15\%; (c): plate at DOP 20\%; (d): plate at DOP 25\%

(a)

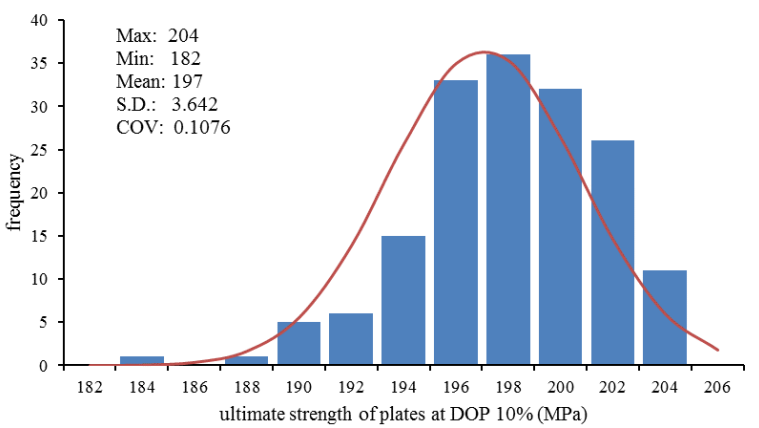

(b)
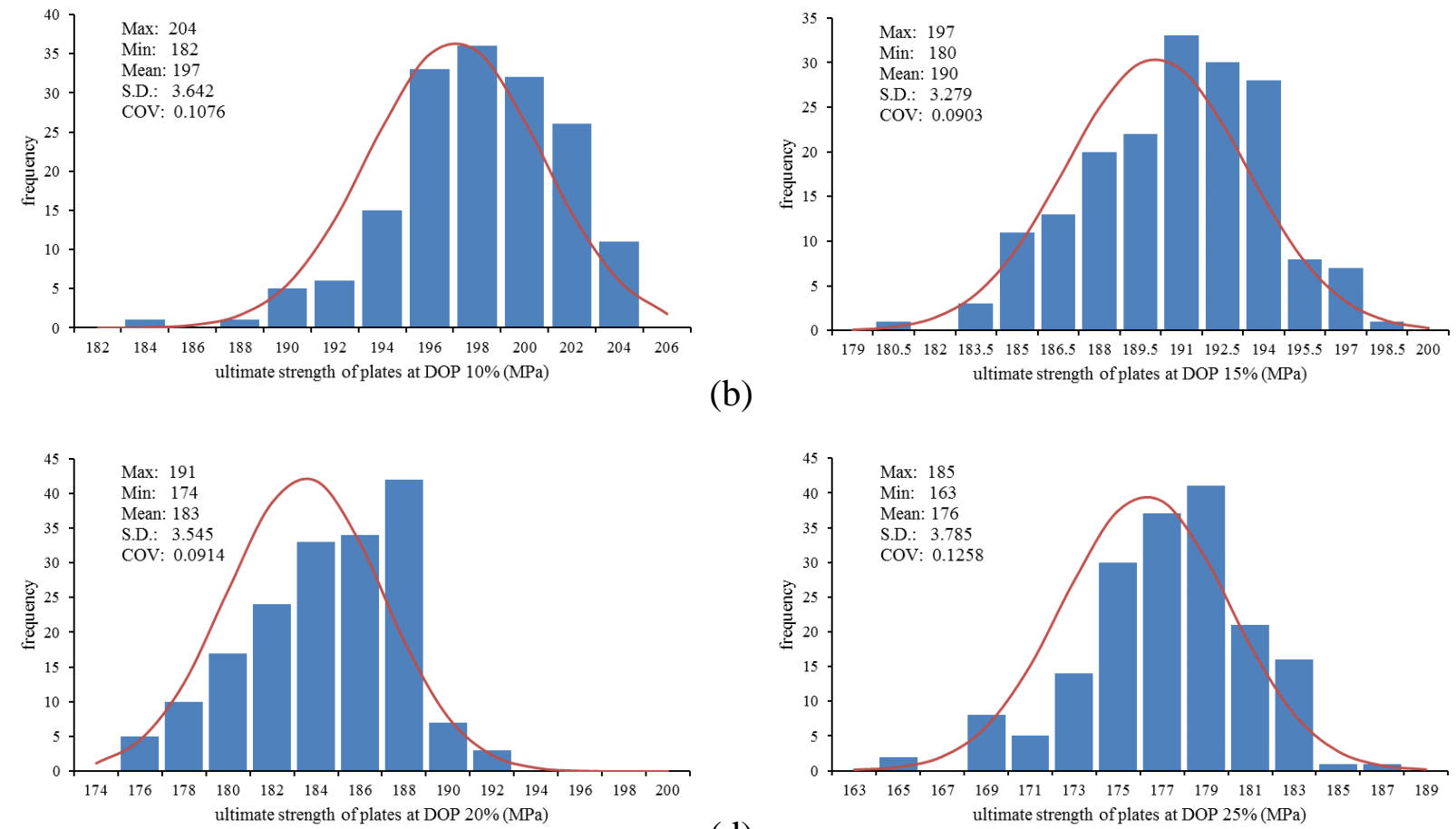

(c)

(d)

Figure 13 Statistical distribution of ultimate strengths of pitted plates under uniaxial compression. (a): DOP 10\%; (b): DOP 15\%; (c) DOP 20\%; (d): DOP 25\% 
(a)
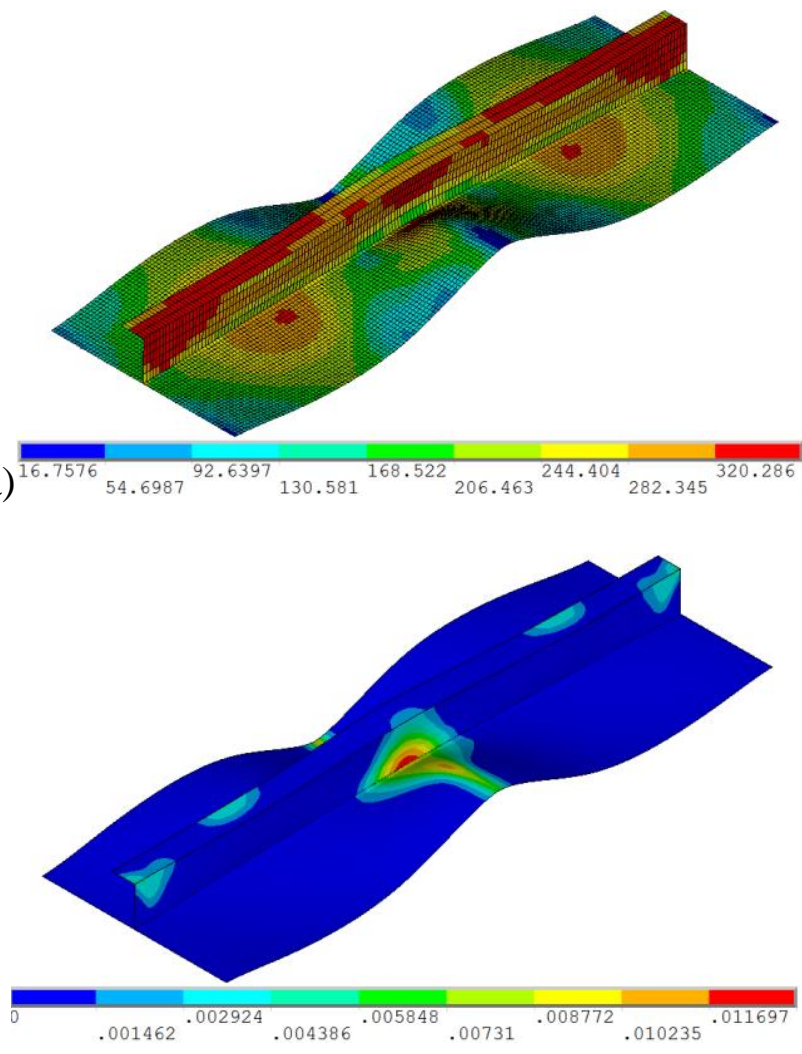

(b)
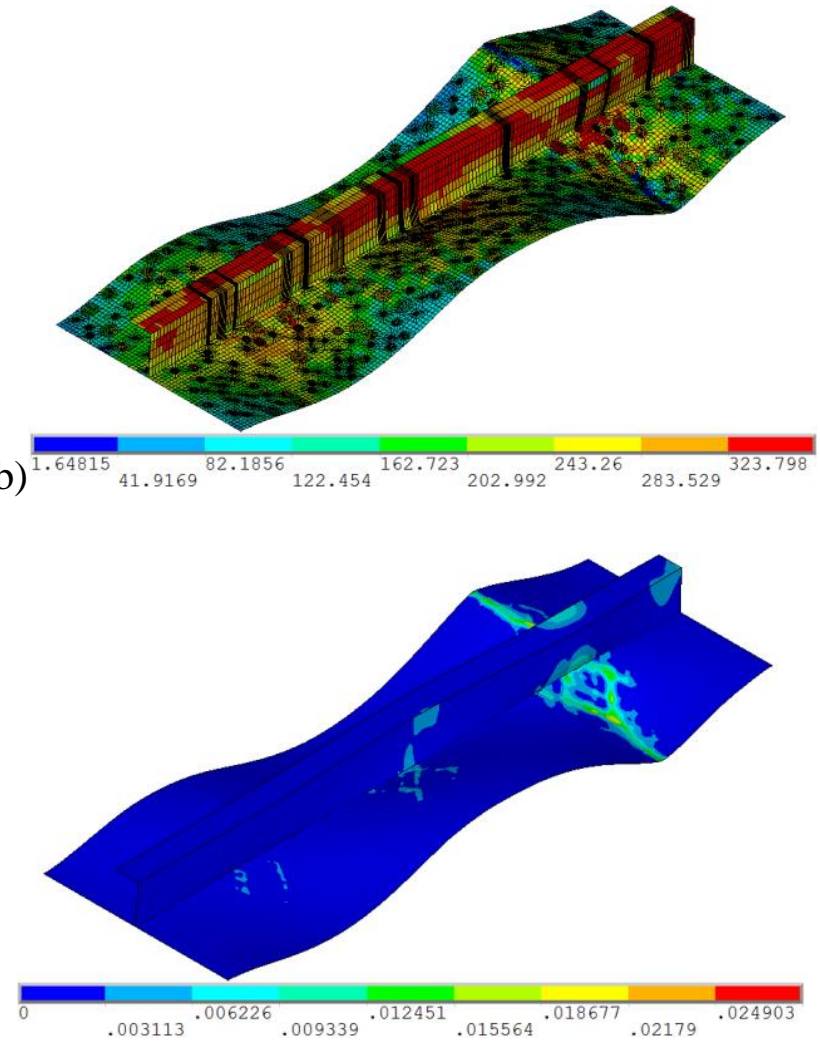

Figure 14 Contour plots of membrane stress (top), plastic strain (bottom) and post-collapse mode. (a): intact panel; (b): pitted panel (DOP 25\%)

(a)

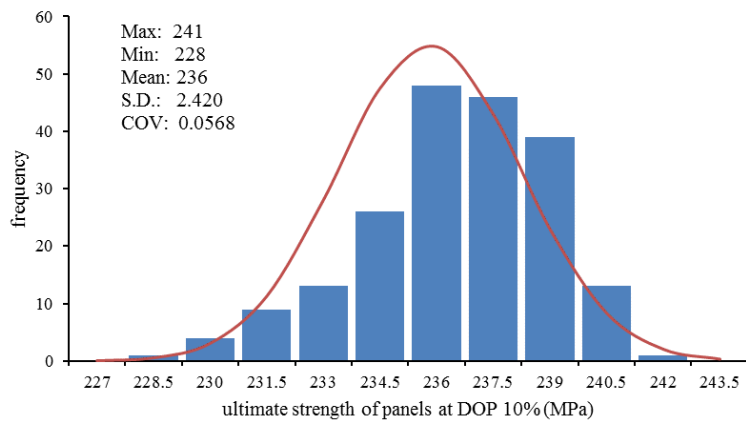

(b)
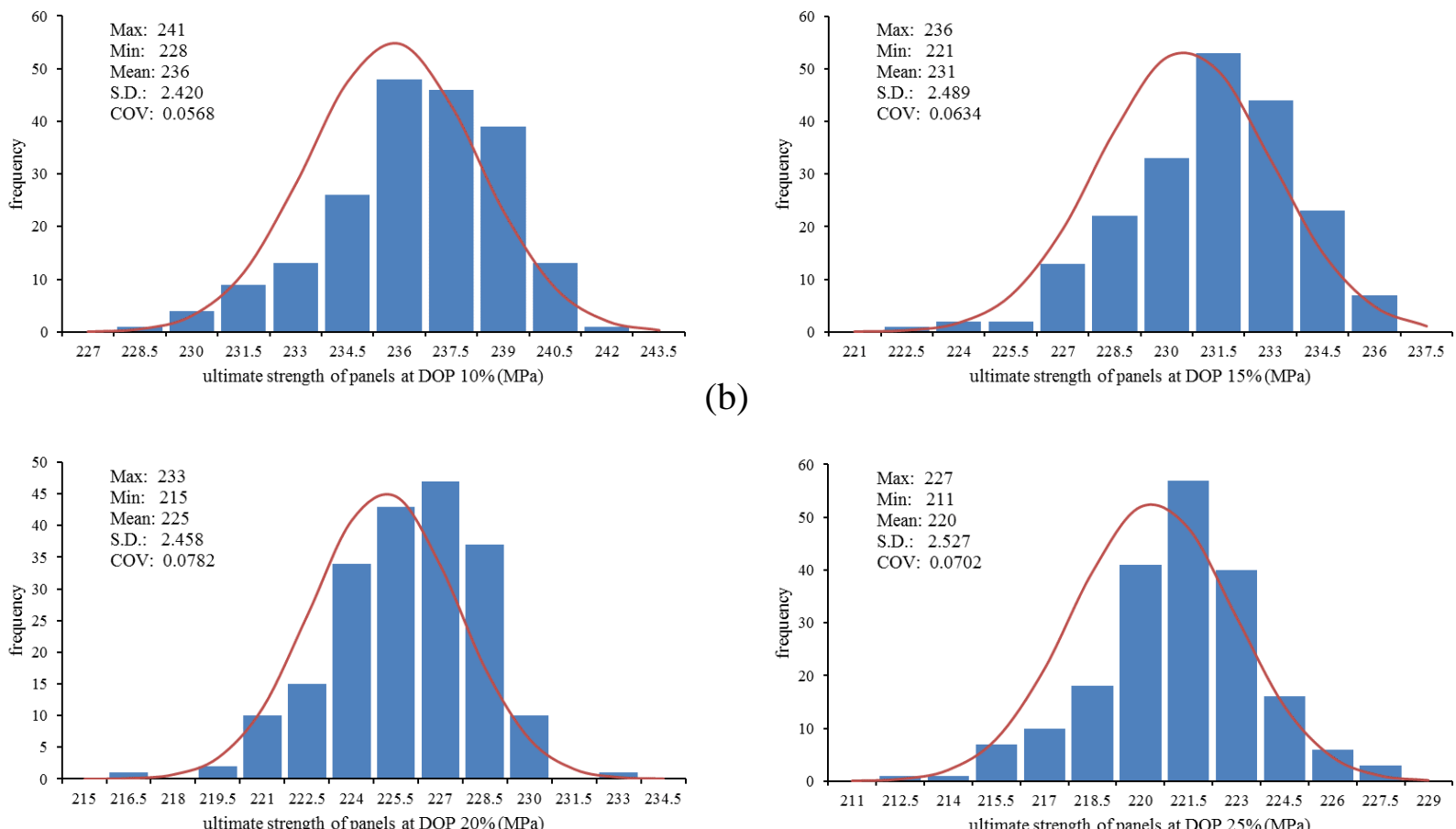

(c)

(d)

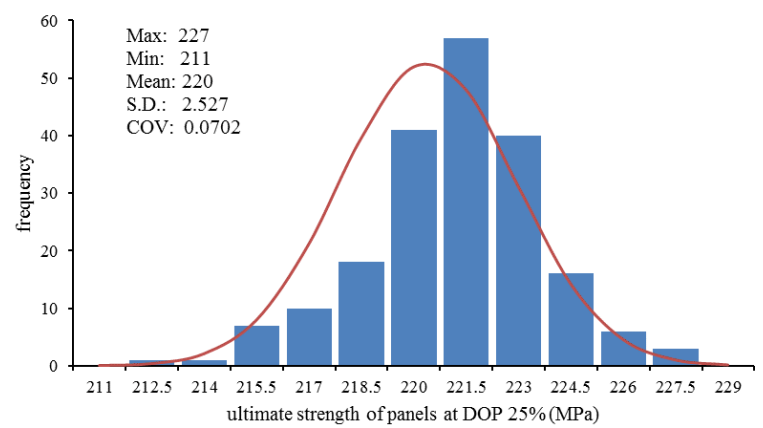

d)

Figure 15 Statistical distribution of ultimate strength of pitted panels under uniaxial compression.

(a): DOP 10\%; (b): DOP 15\%; (c) DOP 20\%; (d): DOP 25\% 


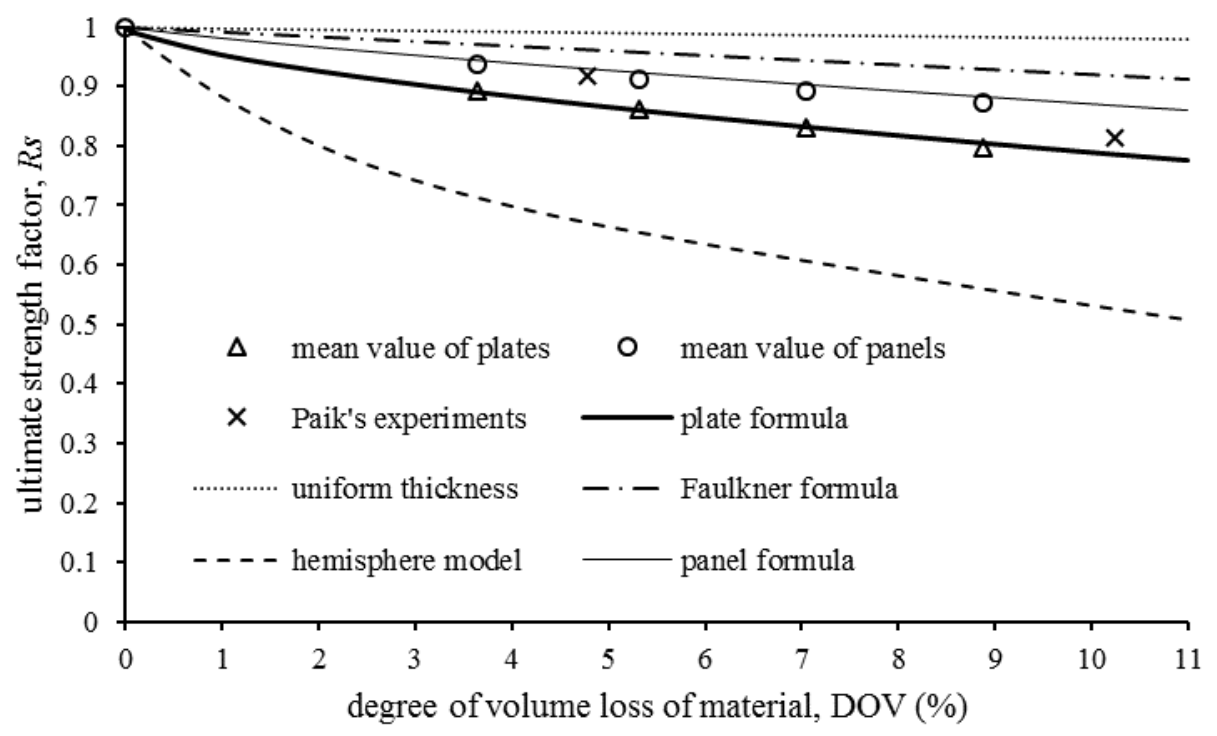

Figure 16 Comparisons of ultimate strength factor between regression formula and existing studies

(a)
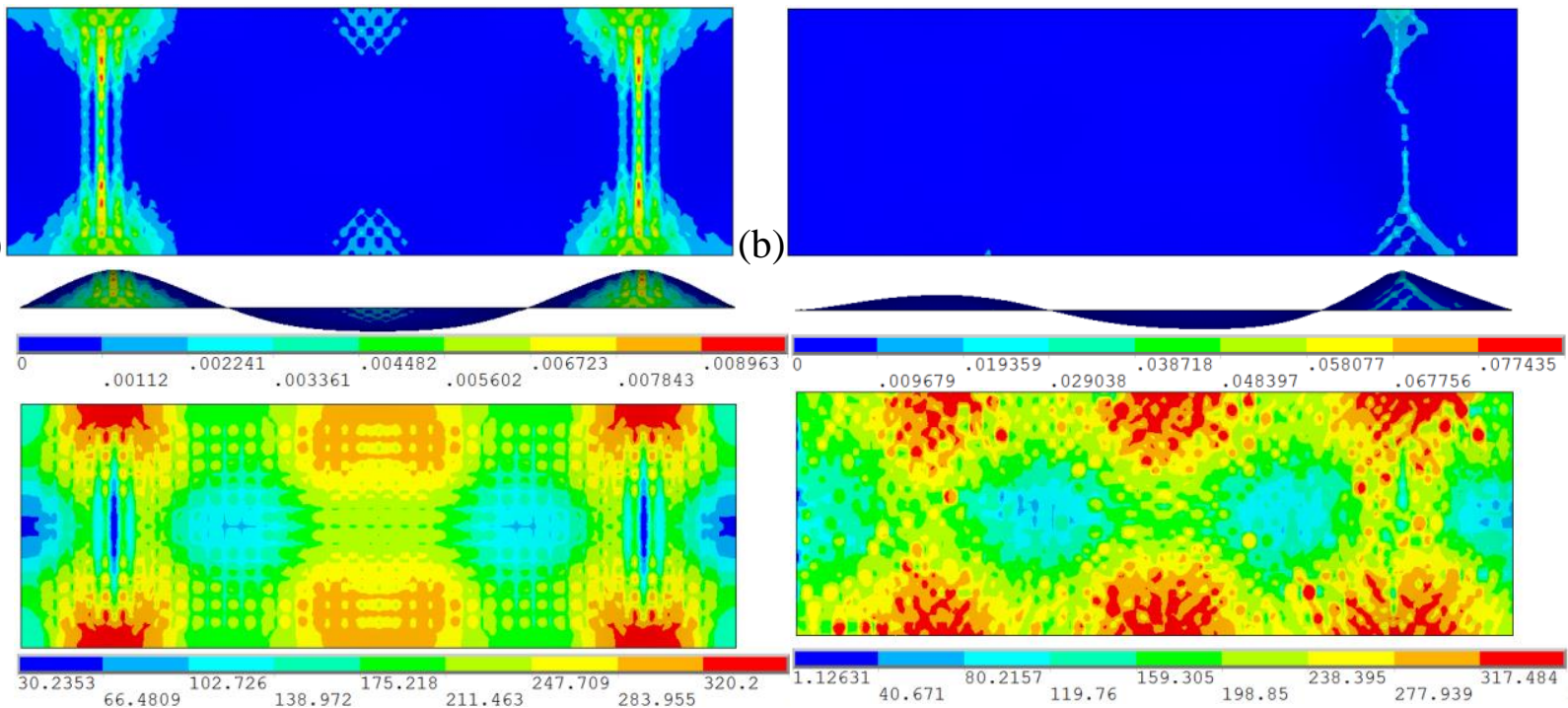

Figure 17 Contour plots of plastic strain (top), post-collapse mode (middle) and membrane stress (bottom; MPa) of plates with DOV 8.87\% at ultimate state. (a): plate with regular pits; (b): plate with random pits. 
Table 1 Meshing algorithms for classified plate with random pitting

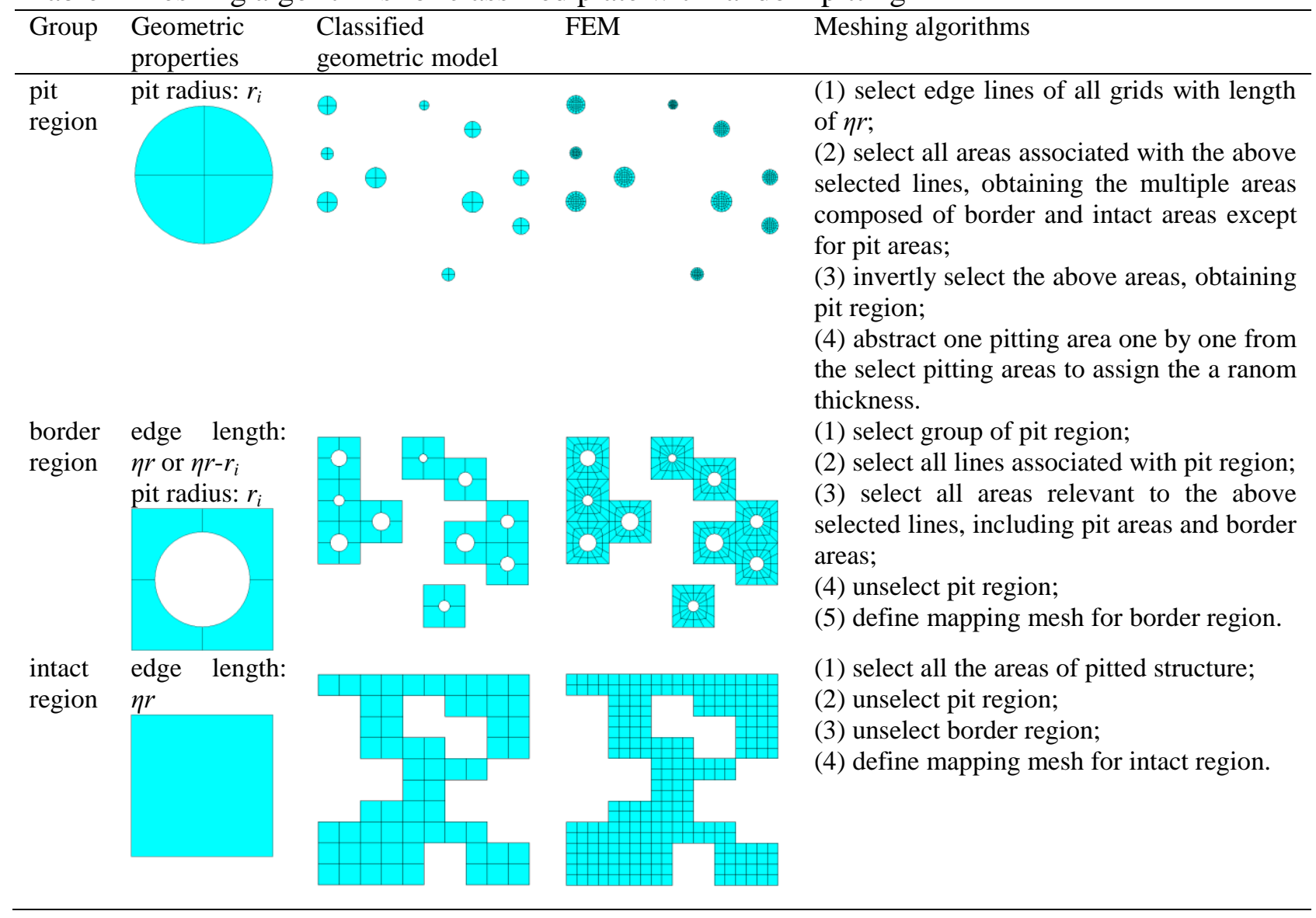

Table 2 Geometric and material properties of plated structures

Properties
Yield stress of plate, $\sigma_{y}=352.8 \mathrm{MPa} ; \sigma_{b}=500 \mathrm{MPa}$
Elastic modulus, $E=205.8 \mathrm{GPa}$
Possion's ratio, $v=0.3$
Plate length, $a=2100 \mathrm{~mm}$
Plate breath, $b=700 \mathrm{~mm}$
Plat thickness, $t=10 \mathrm{~mm}$
Stiffener, $h_{w} \times b_{f} \times t_{w} \times t_{f}=138 \times 90 \times 9 \times 12(\mathrm{~mm})$

Table 3 Boundary conditions of plated structures

\begin{tabular}{lll}
\hline Boundary & Unsitffened plate & Stiffened panel \\
\hline$x=0$ & $U_{x}=U_{y}=R O T_{x}=R O T_{y}=0$ & Symmetric about $x$ axis \\
$x=b$ & $U_{x}=U_{y}=R O T_{x}=R O T_{y}=0$ & Symmetric about $x$ axis \\
$z=0$ & $U_{z}=U_{y}=R O T_{y}=R O T_{z}=0$ & $U_{z}=U_{y}=R O T_{y}=R O T_{z}=0$ \\
$z=a$ & $U_{y}=R O T_{y}=R O T_{z}=0$ & $U_{y}=R O T_{y}=R O T_{z}=0$ \\
\hline
\end{tabular}


Table 4 Convergence analysis of stochastic simulation on mean value of ultimate strength (MPa)

\begin{tabular}{ccccccccc}
\hline \multirow{2}{*}{$\begin{array}{c}\text { Model } \\
\text { amount }\end{array}$} & \multicolumn{4}{c}{ Unstiffened plates } \\
\cline { 2 - 9 } & DOP10\% & DOP15\% & DOP20\% & DOP25\% & DOP10\% & DOP15\% & DOP20\% & DOP25\% \\
\hline 50 & 197.5 & 190.3 & 183.1 & 176.5 & 235.9 & 230.4 & 225.3 & 221.0 \\
100 & 197.3 & 189.8 & 183.5 & 176.5 & 235.8 & 230.4 & 225.3 & 220.4 \\
150 & 197.5 & 189.8 & 183.4 & 176.2 & 235.9 & 230.5 & 225.0 & 220.3 \\
200 & 197.1 & 190.1 & 183.5 & 176.3 & 235.8 & 230.5 & 225.1 & 220.4 \\
\hline
\end{tabular}

Table 5 Statistical properties of ultimate strengths $(\mathrm{MPa})$ at various levels of pitting intensities

\begin{tabular}{|c|c|c|c|c|c|c|c|c|c|c|c|}
\hline \multirow[t]{2}{*}{ DOP } & \multicolumn{5}{|c|}{ Unsitffened plates } & \multicolumn{5}{|c|}{ Stiffened panels } & \multirow{2}{*}{$\frac{R_{s s}-R_{s u}}{R_{s u}}$} \\
\hline & Max & Min & Mean $\left(R_{s u}\right)$ & S.D. & $\mathrm{COV}$ & $\operatorname{Max}$ & Min & Mean $\left(R_{s s}\right)$ & S.D. & $\mathrm{COV}$ & \\
\hline 10 & 204 & 182 & 197(0.893) & 3.642 & 0.1076 & 241 & 228 & $236(0.937)$ & 2.420 & 0.0568 & $4.90 \%$ \\
\hline 15 & 197 & 180 & $190(0.860)$ & 3.279 & 0.0903 & 236 & 221 & $231(0.913)$ & 2.489 & 0.0634 & $6.16 \%$ \\
\hline 20 & 191 & 174 & $183(0.828)$ & 3.545 & 0.0914 & 233 & 215 & $225(0.893)$ & 2.458 & 0.0782 & $7.86 \%$ \\
\hline 25 & 185 & 163 & $176(0.796)$ & 3.785 & 0.1258 & 227 & 211 & $220(0.873)$ & 2.527 & 0.0702 & $9.71 \%$ \\
\hline
\end{tabular}

